\title{
Processing of cloud condensation nuclei by collision-coalescence in a mesoscale model
}

\author{
David B. Mechem, ${ }^{1}$ Paul C. Robinson, ${ }^{1}$ and Yefim L. Kogan ${ }^{1}$ \\ Received 8 February 2006; revised 1 May 2006; accepted 15 June 2006; published 26 September 2006.
}

[1] The Naval Research Laboratory's Coupled Ocean-Atmosphere Mesoscale Prediction System (COAMPS) is employed to explore the relative importance of source, sink, and transport processes in producing an accurate forecast of the aerosol-cloud-drizzle system. Cloud processing, defined to be the reduction of cloud condensation nuclei (CCN) via collision-coalescence, is not uniquely related to total particle concentration, a behavior which stems from the roughly inverse dependence on cloud droplet concentration between autoconversion and accretion depletion terms. Instead, the behavior of cloud processing in COAMPS suggests relationships (scalings) based on cloud base drizzle rate $(R)$ and cloud droplet concentration $\left(N_{c}\right)$. Cloud processing is found to be correlated with drizzle, a relationship that can be represented as a power law for drizzle rates less than $0.6 \mathrm{~mm} \mathrm{~d}^{-1}$. A scaling for cloud processing based on the product of $N_{c}$ and $R$ is accurate over a wider range of drizzle rates. Results from large eddy simulation with sizeresolved microphysical processes demonstrate reasonable agreement with COAMPS and the two parameter scaling. Entrainment plays an important role in strongly modulating the mean marine boundary layer (MBL) concentration, both increasing and decreasing $\mathrm{CCN}$, depending upon the entrainment velocity $w_{e}$ and the difference between MBL and free tropospheric $\mathrm{CCN}$ concentrations. The importance of entrainment suggests that transport processes, especially in the vertical, play a fundamental role in the overall $\mathrm{MBL}$ $\mathrm{CCN}$ balance. In situ sources rates of $\mathrm{CCN}$, taken to represent heterogeneous chemical processes and sea salt flux of submicron size particles from the ocean surface, must be unrealistically large in order to be of the same magnitude as cloud processing. Because of the prevailing importance of cloud processing and entrainment over timescales of a typical mesoscale forecast, we argue that incorporating accurate vertical aerosol profiles into the model update cycles, either from remote sensing or from global chemistry models, is more important than highly constrained local $\mathrm{CCN}$ source rates.

Citation: Mechem, D. B., P. C. Robinson, and Y. L. Kogan (2006), Processing of cloud condensation nuclei by collision-coalescence in a mesoscale model, J. Geophys. Res., 111, D18204, doi:10.1029/2006JD007183.

\section{Introduction}

[2] Atmospheric aerosol that serve as cloud condensation nuclei (CCN) play a significant role in determining the radiative and microphysical properties of marine boundary layer (MBL) clouds [Twomey, 1977; Albrecht, 1989]. Both the first and second indirect effects are in essence the response of cloud properties to the character of the ambient aerosol. The microphysical responses of the cloud to increasing submicron CCN concentrations are an increased number of smaller droplets for a given liquid water content [LWC] (the "Twomey" effect [Twomey, 1977]), and the suppression of precipitation processes associated with reduced coalescence rates (the precipitation suppression or "Albrecht" effect [Albrecht, 1989]). Lower CCN concen-

\footnotetext{
Cooperative Institute for Mesoscale Meteorological Studies, University of Oklahoma, Norman, Oklahoma, USA.

Copyright 2006 by the American Geophysical Union. 0148-0227/06/2006JD007183
}

trations are more conducive to drizzle formation, precipitation, and the resulting effects upon the boundary layer thermodynamic stratification and energetics. One study using large eddy simulation (LES) demonstrated that drizzle processes can sometimes lead to the breakup of a solid cloud deck by stably stratifying the boundary layer into an environment that favors isolated, shallow cumulus updrafts [Stevens et al., 1998]. More recently, Ackerman et al. [2004] found a complicated relationship between precipitation, liquid water path (LWP), and entrainment in simulations of marine stratocumulus. The complex nature of aerosolcloud-drizzle interactions has important implications for understanding cloud-climate feedbacks in global circulation models.

[3] Mechem and Kogan [2003, hereinafter MK2003] demonstrated that a mesoscale model can represent some aspects of these complicated aerosol-cloud-precipitation interactions. Using a two-moment bulk microphysical parameterization [Khairoutdinov and Kogan, 2000], the Naval Research Laboratory's Coupled Ocean-Atmosphere Meso- 
scale Prediction System (NRL COAMPS [Hodur, 1997]) responded to different ambient $\mathrm{CCN}$ concentrations in a physically consistent manner. For conditions characteristic of a clean maritime air mass, the model developed drizzle and a significant degree of mesoscale organization in the form of banded cloud structures. The transition from unbroken stratocumulus to banded cloud structures in the model is analogous to drizzle-induced cloud breakup produced in LES studies. As described above, the aerosolcloud-precipitation feedbacks are thought to be important on global climate scales, but MK2003 demonstrated that this interaction can have significant impact even on shortterm (6-24 hour) mesoscale model forecasts.

[4] These previous studies predominantly focused on how CCN characteristics affect cloud microphysical properties, including precipitation formation and how the resulting precipitation modulates cloud geometry. However, they largely neglected how clouds in turn modify $\mathrm{CCN}$ properties. Clouds affect aerosol size distributions via the physical processes of droplet nucleation, collision-coalescence, and impaction scavenging [Flossmann et al., 1985]. Collisioncoalescence is typically the most important of the three processes. Coalescence reduces droplet concentration and, upon evaporation of the larger droplet, results in fewer CCN relative to the number initially available for nucleating droplets. The nucleus of the evaporated droplet is larger than the original $\mathrm{CCN}$ radius. In other words, collisioncoalescence depletes the number concentration of $\mathrm{CCN}$, but those that remain are larger [Hudson, 1993; Garrett and Hobbs, 1995]. A fewer number of larger CCN will be more conducive to efficient precipitation formation in subsequent cloud cycles for two reasons. First, although the larger particle sizes may not be "activated" in the Köhler sense, they may nevertheless be able to grow large enough to serve as drizzle nuclei. Second, the available liquid water will be distributed among fewer nucleation sites, increasing droplet radius and collision efficiency [Feingold et al., 1996]. In the absence of a CCN source, collision-coalescence can lead to what Feingold and Kreidenweis [2002] term a "runaway" precipitation process.

[5] In the absence of collision-coalescence, scavenging, and heterogeneous chemistry, nucleation does not modify the aerosol distribution per se, since evaporating the nucleated droplets will recover the original aerosol properties. The magnitude of cloud processing via impaction scavenging, which represents liquid drops "capturing" aerosol through various mechanisms, is generally much less than that from collision-coalescence and is neglected as in the work by Feingold et al. [1996]. In addition to these physical mechanisms, aqueous chemical reactions can increase dissolved solute mass in droplets [Hegg and Hobbs, 1982; Feingold et al., 1996]. Feingold et al. found that, under some circumstances, the increases in regenerated CCN mass from collision-coalescence and aqueous phase chemistry can be of similar magnitude.

[6] The atmospheric aerosol state in the marine boundary layer is a balance between sources, sinks, and transport. Sources from aqueous phase chemistry and sinks attributable to collision-coalescence are discussed above. In addition, sea spray and di-methyl sulfide (DMS) generation [Pandis et al., 1994; O'Dowd et al., 1997] are a source of $\mathrm{CCN}$ or $\mathrm{CCN}$ precursors at the surface interface, while free tropospheric aerosols serve as a source to an entraining MBL [Hudson, 1993; Raes, 1995]. Entrainment should be considered a (turbulent) transport term, which can be negative when the free tropospheric $\mathrm{CCN}$ concentration is less than that in the MBL. Clarke et al. [1996] found that entrainment dilution was a key factor in a $35 \%$ reduction of column mean aerosol over a 34 hour period in the Atlantic Stratocumulus Transition Experiment (ASTEX). Hoell et al. [2000] argued that a reduction in MBL accumulation mode aerosol from 670 to $430 \mathrm{~cm}^{-3}$ arose primarily from entrainment dilution. This dilution effect has also been noted by Van Dingenen et al. [1999] and Johnson et al. [2000].

[7] This study employs COAMPS to explore the balance between these source, sink, and transport processes in the context of determining the sensitivities of a mesoscale forecast of the aerosol-cloud-precipitation system. MBL aerosol budgets are calculated for simulations with different initial aerosol concentrations and various source mechanisms and magnitudes. Our results demonstrate robust relationships (scalings) between cloud processing and drizzle, the importance of elevated sources of pollution, entrainment dilution, and generally the inability of in situ MBL and surface sources to overcome depletion via cloud processing. For the purposes of forecasting, we argue that incorporating estimates of the vertical aerosol profile into model update cycles, either from remote sensing or global chemistry models, may be more important than highly constrained local CCN source rates.

\section{Mesoscale Model Configuration}

[8] Simulations to investigate cloud processing of aerosol are based on the version of COAMPS used in MK2003. COAMPS is a fully three-dimensional, nonhydrostatic, compressible mesoscale model that integrates the acoustically active terms using the mode-splitting technique. A 1.5order turbulence closure scheme, which includes a prognostic equation for turbulent kinetic energy, parameterizes subgridscale motions (Mellor and Yamada [1982], "Level 2.5"). At the grid spacing used here, most of the turbulent transport is unresolved, so the turbulence closure is a crucial element in correctly representing the entrainment of free tropospheric air into the MBL. MK2003 demonstrated that the COAMPS subgrid-scale (SGS) scheme responds qualitatively correctly to drizzle-induced thermodynamic stratification in the MBL. Longwave radiation is treated according to Harshvardhan et al. [1987].

\subsection{Microphysical Parameterization}

[9] COAMPS employs the bulk microphysical parameterization of Khairoutdinov and Kogan [2000, hereinafter referred to as $\mathrm{KK}]$. $\mathrm{KK}$ is a partial moment scheme that sequesters liquid water into nonprecipitating (cloud) and precipitating (drizzle) components. The microphysical scheme comprises prognostic equations for cloud and drizzle water content $\left(q_{c}\right.$ and $\left.q_{r}\right)$, cloud and drizzle number concentration $\left(N_{c}\right.$ and $\left.N_{r}\right)$, and $\mathrm{CCN}$ concentration $\left(N_{C C N}\right)$. Wood [2005b] found good agreement between microphysical process rates (autoconversion and accretion) from the KK parameterization and those derived from the stochastic collection equation applied to aircraft particle probe data. Our prognostic equations also include fallspeed relations for 


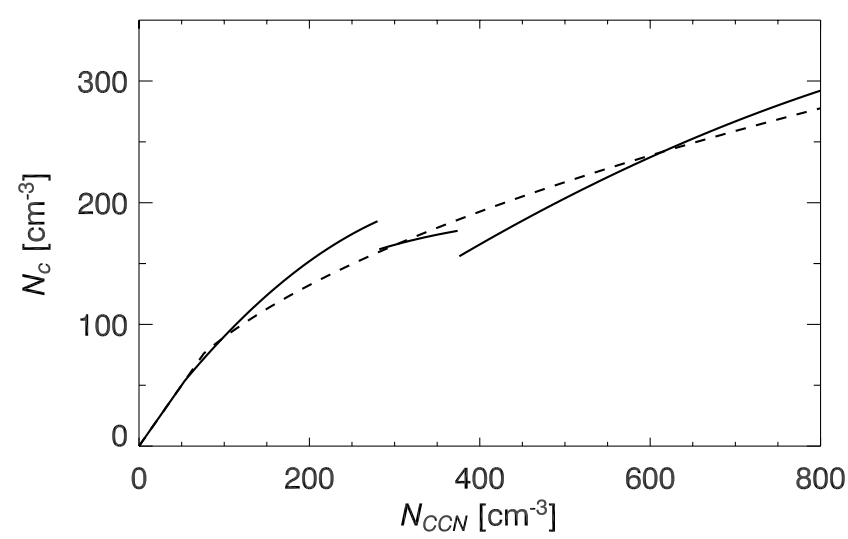

Figure 1. Nucleation parameterization, which comprises an empirically based relationship between $\mathrm{CCN}$ and cloud droplet concentration. Dashed line represents a power law fit to the piecewise discontinuous curves.

$q_{r}$ and $N_{r}$. Although recent LES results suggest that cloud droplet sedimentation may play a role in correctly representing in-cloud turbulence [Ackerman et al., 2004], this term has been neglected in the present study.

[10] As in MK2003, nucleation of cloud droplets from $\mathrm{CCN}$ is based on the empirical relations of Martin et al. [1994] and O'Dowd et al. [1996] that relate bulk CCN to cloud droplet number concentrations. We slightly modify the range of the Martin et al. formulation to ensure that $N_{c} \leq$ $N_{C C N}$ :

$$
\begin{array}{ll}
N_{c}=-1.15 \times 10^{-3} N_{C C N}^{2}+0.963 N_{C C N}+5.30 & 54 \leq N_{C C N} \leq 280 \\
N_{c}=197.0\left(1-e^{-6.13 \times 10^{-3} N_{C C N}}\right) & 280<N_{C C N}<375 \\
N_{c}=-2.10 \times 10^{-4} N_{C C N}^{2}+0.568 N_{C C N}-27.9 & 375 \leq N_{C C N} \leq 1500
\end{array}
$$

For $N_{C C N}<54 \mathrm{~cm}^{-3}, N_{c}=N_{C C N}$. Although this piecewise nucleation parameterization (Figure 1) is discontinuous at 280 and $375 \mathrm{~cm}^{-3}$, our simulation results show little difference when using the simple power law approximation of $N_{c}=\operatorname{MIN}\left(N_{C C N}, 10.8 N_{C C N}^{0.494}-15.5\right)$ (overlaid in Figure 1). Because of the tight coupling between cloud droplets and $\mathrm{CCN}$, we confine most of our analysis of cloud processing to total concentration $N_{t}=N_{C C N}+N_{c}$. For the purposes of this study, the terms "CCN" and "aerosol" are used interchangeably, since activation according to equation (1) assumes the aerosol is chemically homogeneous and microphysically active.

[11] Simple diagnostic relations between $\mathrm{CCN}$ and droplet number have been commonly used to represent droplet nucleation, particularly in global climate model studies [Jones et al., 1994; Lieput and Lohmann, 2001]. This method of nucleation is limited in that it does not respond directly to model dynamics, and as a result the cloud droplet and $\mathrm{CCN}$ concentration fields are constrained more rigidly than in nature. However, for the purpose of the current investigation that focuses on the dependence of cloud processing rates on cloud microstructure and drizzle, representing in detail the nucleation mechanisms is not important so long as the nucleation scheme results in a full range of cloud droplet concentration and drizzle rate parameters. Future efforts will incorporate a more complete method of nucleation that responds to model dynamics, in addition to $\mathrm{CCN}$ properties.

[12] The cloud processing of aerosol (or just cloud processing for short) in MK2003 represents droplet nucleation and collision-coalescence as follows. Aerosols are activated according to the simple empirical relations, nucleating a specific cloud droplet number concentration $N_{c}$. The process of collision-coalescence is represented in the bulk model by the mechanisms of autoconversion and accretion, which reduce the concentration $N_{c}$. CCN are regenerated upon droplet evaporation, which as a result of collision-coalescence will be fewer than the original number. $\mathrm{CCN}$ associated with drizzle drops that fall to the ground without evaporating are no longer available for nucleating droplets. Subsequent cloud cycles occurring in an environment of depleted CCN concentrations are more conducive to precipitation formation.

[13] All aerosol properties are represented in COAMPS by a simple number concentration, so naturally many aspects of aerosol properties (such as the shift of the spectral shape toward larger sizes) are currently ignored. In this work, we concentrate on the sink of CCN concentration due to collision-coalescence. While aerosol spectral shape and mean radius may influence nucleation characteristics, their direct bearing on cloud processing from collisioncoalescence is limited.

\subsection{Experimental Configuration}

[14] The experimental configuration is similar to those used in recent idealized studies of mesoscale convective cells (MCCs). Fiedler and Khairoutdinov [1994] investigated MCCs using a dimensionless, three-dimensional, horizontally periodic model that was effectively $(16 \mathrm{~km})^{2}$ square with $125 \mathrm{~m}$ grid spacing in the horizontal. Müller and Brümmer [1999] employed a three-dimensional model with a square domain with sides of $12.8 \mathrm{~km}$ and horizontal grid spacing of $200 \mathrm{~m}$. Shao and Randall [1996] used a two-dimensional model with a width of $32 \mathrm{~km}$ and horizontal grid spacing $250 \mathrm{~m}$. The present study follows the method used in the idealized simulations by Fiedler and Kong [2003], who investigate MCCs over 32 and $64 \mathrm{~km}$ domains with $2 \mathrm{~km}$ horizontal grid spacing. The experimental configuration of Fiedler and Kong [2003] and the present study are very similar to those used in LES experiments [e.g., Moeng et al., 1996; Stevens et al., 2005], where thermodynamic profiles, wind, and large-scale forcings are specified, along with some small level of background turbulence to initialize the simulation.

[15] Initial conditions based on a cloud-topped boundary layer (CTBL) from the Atlantic Stratocumulus Transition Experiment (ASTEX) (A209 case sounding [Duynkerke et al., 1995]) are specified using the conservative thermodynamic variables liquid water virtual potential temperature $\left(\theta_{v l}\right)$ and total water $\left(q_{t}\right)$ (Table 1). Initial profiles of the COAMPS thermodynamic variables potential temperature, water vapor mixing ratio, and cloud water mixing ratio, are calculated from these specified profiles of $\theta_{v l}$ and $q_{t}$. Like LES experiments, the specified initial conditions contain cloud; here the MBL is initially well mixed (constant $\theta_{v l}$ and $q_{t}$ ) and topped by a cloud with a peak adiabatic LWC of 
Table 1. Initial Thermodynamic Profile for All COAMPS Experiments

\begin{tabular}{lll}
\hline Height, $\mathrm{m}$ & $\theta_{v l}, \mathrm{~K}$ & $q_{t}, \mathrm{~g} \mathrm{~kg}^{-1}$ \\
\hline 0.0 & 289.8 & 10.2 \\
662.5 & 289.8 & 10.2 \\
687.5 & 295.0 & 9.1 \\
1500.0 & 299.9 & 6.83 \\
\hline
\end{tabular}

$0.6 \mathrm{~g} \mathrm{~m}^{-3}$. Initial conditions are horizontally homogeneous, except for random temperature and turbulent kinetic energy perturbations with amplitude $0.05 \mathrm{~K}$ and $1.0 \mathrm{~m}^{2} \mathrm{~s}^{-2}$, respectively, imposed for all heights less than $100 \mathrm{~m}$. The initial mean wind is zero. Surface sensible and latent heat fluxes are 10 and $25 \mathrm{~W} \mathrm{~m}^{-2}$, respectively. Large-scale subsidence divergence of $5 \times 10^{-6} \mathrm{~s}^{-1}$ is imposed throughout the domain. For the purposes of the radiative transfer calculations, nocturnal conditions are assumed with a constant SST of $286 \mathrm{~K}$.

[16] COAMPS simulations are performed on a three dimensional Cartesian grid of $50 \times 50 \times 61$ with horizontal grid spacing of $2 \mathrm{~km}$ and a vertical spacing of $25 \mathrm{~m}$. Because some of the lateral edge points are used for the boundary condition, the effective physical domain volume is $90 \times 90 \times$ $1.5 \mathrm{~km}^{3}$. Three dimensional simulations are necessary to capture the drizzle-induced mesoscale variability reported in MK2003. Lateral boundary conditions are periodic, and the upper boundary is a rigid lid, with a region of damping imposed over the upper portion of the domain. All the simulations are for a 12 hour period.

[17] The initial spatial distributions of CCN concentrations are specified for the MBL and the free troposphere, determined by the inversion height $z_{i}$. The height of the inversion is defined by cloud top height, as specified by a cloud water threshold of $0.01 \mathrm{~g} \mathrm{~kg}^{-1}$. Initially, $z_{i}$ is $662.5 \mathrm{~m}$ but rises as the simulations progress and the boundary layer entrains. In the first set of experiments, the $\mathrm{CCN}$ concentration in the MBL is initially set to a value ranging from 100 to $800 \mathrm{~cm}^{-3}$, with the free tropospheric concentration set to zero (simulations C100, C200, C400, C800, CND). These experiments are intended to represent an MBL with no $\mathrm{CCN}$ sources. In a second suite of experiments, the initial MBL concentration is $200 \mathrm{~cm}^{-3}$ and the free tropo- spheric concentration is varied between zero and $800 \mathrm{~cm}^{-3}$ (simulations E0, E200, E400, and E800. Note that the configuration of E0 is equivalent to C200). These simulations illustrate the effect of entraining "polluted" free tropospheric air into the boundary layer. This polluted air acts as a reservoir of CCN [Hudson, 1993] which, depending on the entrainment rate and free tropospheric concentration, can offset the depletion from cloud processing. A third set of experiments examines the effect of a boundarylayer-wide (in situ) source of CCN (simulations S0, S50, $\mathrm{S} 100, \mathrm{~S} 200$, and S400). These simulations are initially identical to $\mathrm{C} 200$, but during each time step a fixed CCN source term is added over depth of the MBL. These experiments are designed to determine the source magnitude needed to offset depletion of CCN over the 12-hour run time. Table 2 summarizes all simulations.

\section{Cloud Processing in Absence of $\mathbf{C C N}$ Sources 3.1. Effect of Ambient Aerosol Concentration on Cloud Parameters}

[18] A sample cross section of the cloud structure at 12 hour in the C200 simulation (Figure 2) shows the development of substantial mesoscale variability in the form of spatially varying cloud thickness and cloud water mixing ratio $\left(q_{c}\right)$. Thicker cloud and higher values of $q_{c}$ in Figure $2 \mathrm{a}$ tend to be associated with stronger drizzle (Figure 2b). These cloud and drizzle structures are similar to those in Figures 912 of MK2003.

[19] Domain-mean cloud boundaries, LWP, and cloud base drizzle rate all respond in a qualitatively reasonable fashion to changes in ambient aerosol concentration (Figure 3). Cloud boundaries are identified column-bycolumn where cloud droplet concentration $N_{c}$ is greater than $1 \mathrm{~cm}^{-3}$. These column-by-column values are then averaged to obtain the domain-mean quantities. For the COAMPS simulations, this $N_{c}$ threshold typically coincides with a $q_{c}$ threshold of $0.01 \mathrm{~g} \mathrm{~kg}^{-1}$. Thus either quantity can serve to accurately diagnose cloud boundaries and inversion height.

[20] Lower CCN concentrations are associated with larger drizzle rates, reduced entrainment, higher and more variable mean cloud bases, and a reduction in mean LWP. In the

Table 2. Summary of CCN Configurations for the Idealized COAMPS Simulations ${ }^{\mathrm{a}}$

\begin{tabular}{cccc}
\hline Simulation Name & Initial $z<z_{i} N_{C C N}, \mathrm{~cm}^{-3}$ & Initial $z>z_{i} N_{C C N}, \mathrm{~cm}^{-3}$ & Source Rate, $\mathrm{cm}^{-3} \mathrm{~d}^{-1}$ \\
\hline C100 & 100 & & \\
C200 & 200 & & \\
C400 & 400 & & \\
C800 & 800 & & \\
CND & - & 0 & \\
E0 & 200 & 200 & \\
E200 & 200 & 400 & \\
E400 & 200 & 800 & \\
E800 & 200 & & 50 \\
S0 & 200 & & 100 \\
S50 & 200 & & 200 \\
S100 & 200 & & \\
S200 & 200 & & \\
S400 & 200 & & \\
\hline
\end{tabular}

${ }^{\mathrm{a}} \mathrm{C} 200$, E0, and S0 simulations are equivalent. CND corresponds to a simulation using simple saturation adjustment. 

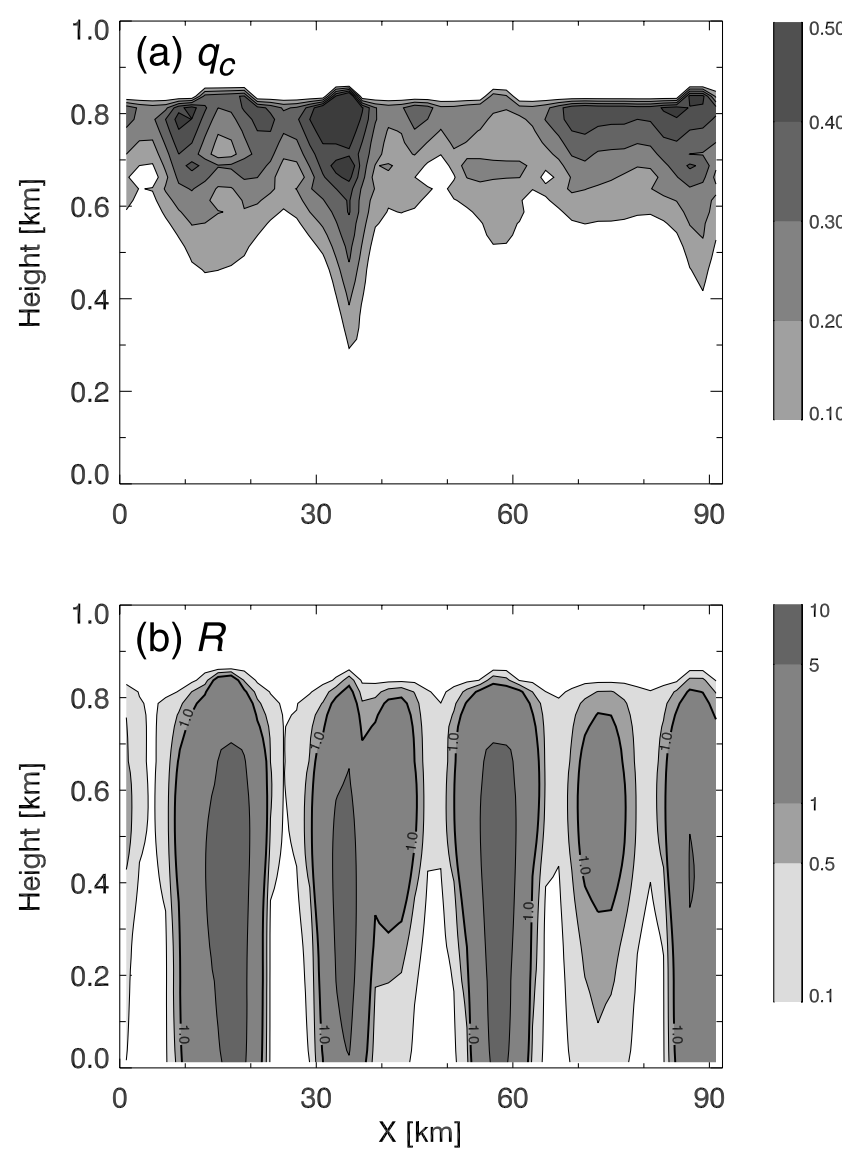

Figure 2. Vertical cross section taken through the C200 domain at 12 hours. (a) Cloud water $\left(\mathrm{g} \mathrm{kg}^{-1}\right)$ and (b) drizzle rate $\left(\mathrm{mm} \mathrm{d}^{-1}\right)$.

cleanest case (C100), entrainment is reduced to the extent that cloud top descends under the effect of large-scale subsidence. The cloud fields in the strongly drizzling cases tend to be highly variable in space and contain regions of much higher LWP (thicker cloud and/or larger $q_{c}$ ), interspersed between regions of very thin (or broken) cloud (e.g., Figure 2a). This variability is not reflected in the mean LWP time series. However, the effect of variability is evident in the drizzle rate time series (Figure $3 \mathrm{~d}$ ). These drizzle rate pulses result from the emergence of mesoscale organization and resolved updrafts and downdrafts brought on by the thermodynamic stratification caused by evaporating drizzle. How COAMPS represents this organized mesoscale aspect of the circulation was discussed in detail in MK2003.

[21] The baseline experiments exhibit dramatic reductions of MBL-mean total particle concentration $N_{t}\left(N_{t}=N_{c}+\right.$ $\left.N_{C C N}\right)$ with time, as illustrated in Figure 4 for simulations $\mathrm{C} 200$ and C800. In both cases the boundary layer deepens (Figures 4a and 4b) and the cloud thickens with time. Even under the presence of warming and drying via entrainment, the longwave radiative forcing at cloud top is sufficient to cool the boundary layer, reducing the saturation mixing ratio and resulting in a thickening of the cloud. The maximum $q_{l}$ is smaller in the $\mathrm{C} 200$ case, which is likely related to drizzle removing water from the cloud layer from 6 hours onward (drizzle rate $R$ in Figure 4c). Drizzle processes are evidently suppressing boundary layer energetics to a degree that entrainment is slightly reduced (see the slight difference in cloud tops in Figures $4 \mathrm{a}$ and $4 \mathrm{~b}$ ). This is occurring through both stably stratifying the boundary layer, and by reducing cloud LWC and the commensurate radiative cooling that drives the boundary layer energetics and entrainment.

[22] In the case of lower initial CCN (C200), $N_{t}$ is initially $200 \mathrm{~cm}^{-3}$ but decreases to less than $40 \mathrm{~cm}^{-3}$ in the upper part of the MBL (Figure 4e). $N_{t}$ in experiment C800 (Figure 4f) over the upper part of the MBL decreases from $800 \mathrm{~cm}^{-3}$ to less than $480 \mathrm{~cm}^{-3}$. The absolute depletion of MBL $N_{t}$ is greater in C800, although the fractional depletion is greater in C200. By 12 hours, the C200 simulation develops a vertical gradient in $N_{t}$, while remaining nearly well mixed in C800.

[23] Because of the low aerosol load, drizzle production is greater in C200, and drizzle drops falling through the subcloud layer (Figure 4c) evaporate and stably stratify the MBL, as evident in the $\theta_{l}$ field from 6 to 12 hours in Figure $4 \mathrm{~g}$. Evaporating drizzle cools the subcloud layer as the simulation progresses. The upper part of the PBL experiences warming episodes from 6 to 8 hours and over the last 3 hours of the simulation, further enhancing the MBL stratification. MK2003 found that the warming at upper levels in the mesoscale model resulted from mechanical entrainment of free tropospheric air from weak mesoscale downdrafts rather than the potential buoyancy argument of Stevens et al. [1998], in which drizzle removes
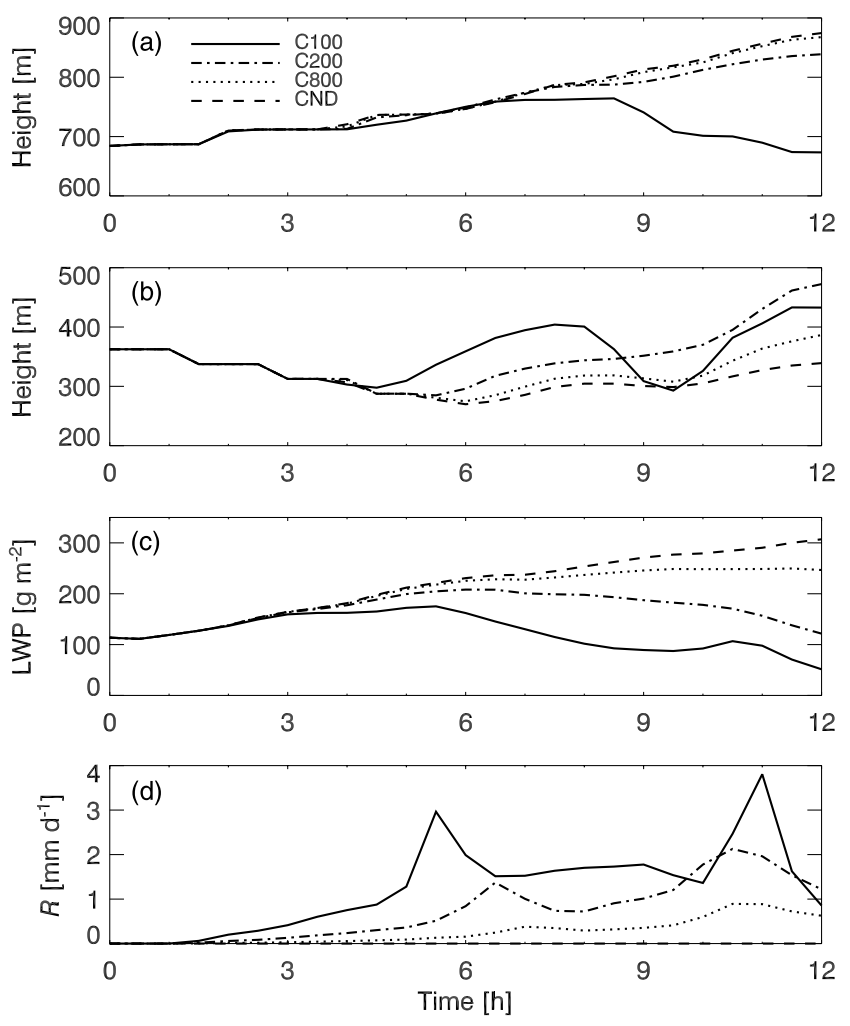

Figure 3. Time series for idealized COAMPS simulations. (a) Cloud top height, (b) cloud base height, (c) LWP, and (d) cloud base drizzle rate. 
C200
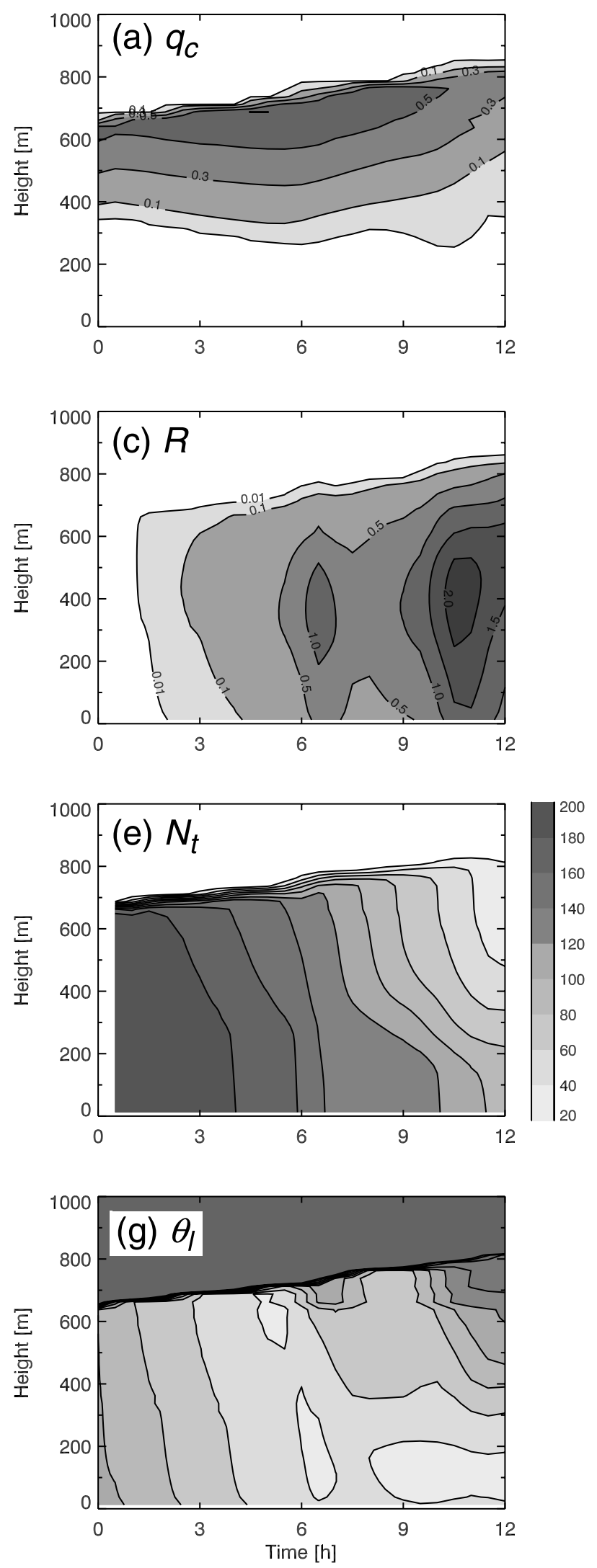

C800
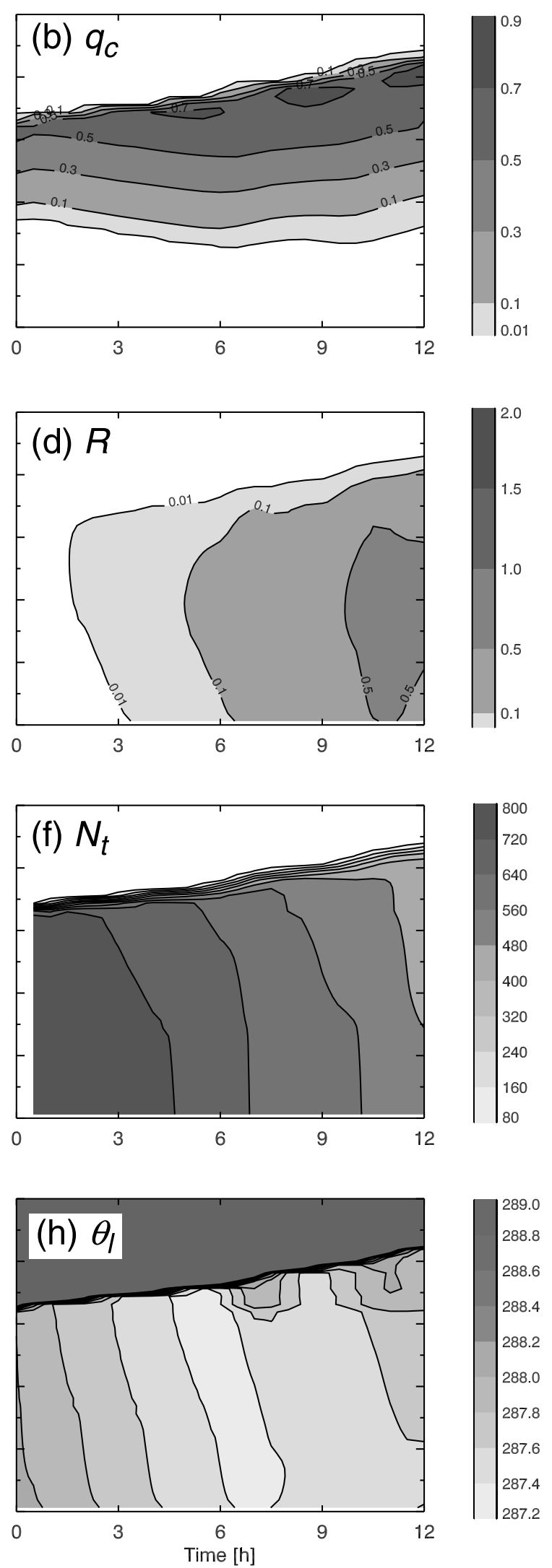

Figure 4. Time-height plots of horizontally averaged quantities for simulations C200 and C800. (a and b) $q_{\mathrm{c}}\left(\mathrm{g} \mathrm{kg}^{-1}\right),\left(\mathrm{c}\right.$ and d) $R\left(\mathrm{~mm} \mathrm{~d}^{-1}\right)$, (e and f) $N_{\mathrm{t}}\left(\mathrm{cm}^{-3}\right)$, and $\left(\mathrm{g}\right.$ and h) $\theta_{l}(\mathrm{~K})$. 
significant water substance from the cloud such that the descending branches of the MBL circulation become dry adiabatic at levels above the mean cloud base, thus warming the cloud layer. This thermodynamic stratification is typically accompanied in LES studies by a decoupling of the MBL-deep eddies into separate subcloud and cloud layer circulations. At the $2 \mathrm{~km}$ grid spacing used here, much of the energy associated with the turbulent eddies is subgridscale, although COAMPS does produce nonnegligible gridscale velocities. MK2003 argued that these resolved updrafts and downdrafts represent the mesoscale structure of MBL clouds, rather than the MBL eddies themselves. The thermodynamic stratification and decoupling of the circulation set the stage for shallow cumulus convection by creating a potentially unstable layer near the surface, which Stevens et al. [1998] documented using LES. Although we do not show cross sections depicting the evolution of the detailed cloud structures, the evolution of the COAMPS cloud structures in Figure 4 is consistent with the findings of MK2003. We refer the reader to MK2003 for a thorough analysis of the phenomenology.

\subsection{Evaluation of Cloud Processing Rates From Budget Analysis}

[24] The total depletion of particles shown in Figures 4e and $4 \mathrm{f}$ is a sum of cloud processing (collision-coalescence) and dilution due to the entrainment of clean air from above. We quantify the evolution of $\mathrm{CCN}$ by contributions from cloud processing, entrainment/mixing, and other sources and sinks by calculating a budget of MBL total particle concentration $N_{t}$. Assuming periodic lateral boundary conditions, the mean $N_{t}$ budget is represented by

$$
\frac{d\left\langle N_{t}\right\rangle}{d t}=\left.\frac{d\left\langle N_{t}\right\rangle}{d t}\right|_{\text {cloud proc. }}+\left.\frac{d\left\langle N_{t}\right\rangle}{d t}\right|_{\text {turb }}+\left.\frac{d\left\langle N_{t}\right\rangle}{d t}\right|_{\text {source/sink }},
$$

where the terms are the rates of change in MBL concentration and the rates due to cloud processing, turbulent transport/mixing, and any other sources or sinks. The term on the left hand side is known, as are any specified sources or sinks. The turbulent transport term is determined from mixing theory, based on the inversion height and the imposed large-scale divergence. The decrease in MBLmean $N_{t}$ concentration from cloud processing is then evaluated as a residual. Each term in equation (2) (except the cloud processing residual) is evaluated using a local, column-by-column identification of cloud top based on a cloud droplet concentration threshold of $1 \mathrm{~cm}^{-3}$, which effectively identifies the inversion base. This method ensures that the MBL mean budget calculation samples all of the MBL and does not inadvertently capture any of the free troposphere, as might occur if a domain-mean cloud top were used. Since we are primarily concerned with cloud and precipitation effects on $\mathrm{CCN}$, dry deposition effects are ignored in equation (2). This is consistent with the relatively small contribution of this term to the MBL aerosol budget given by Hoell et al. [2000]. All terms are calculated over a 12 hour period using analysis intervals of $30 \mathrm{~min}$.

[25] From simple notions of mixing boundary layer air with an incremental volume of free tropospheric air (see Raes [1995], Van Dingenen et al. [1999], and Hoell et al.
[2000] for similar developments), the turbulent transport term in equation (2) can be represented as

$$
\left.\frac{d\left\langle N_{t}\right\rangle}{d t}\right|_{t u r b}=\frac{w_{e}}{z_{i}}\left(N_{F T}-\left\langle N_{t}\right\rangle\right)
$$

where $w_{e}$ is entrainment velocity, $z_{i}$ is the inversion height, and $N_{F T}$ is the free tropospheric CCN concentration. The entrainment velocity $w_{e}$ can be calculated from the time rate of change of the inversion height and the subsidence velocity, so equation (3) becomes

$$
\left.\frac{d\left\langle N_{t}\right\rangle}{d t}\right|_{\text {turb }}=\frac{\frac{d z_{i}}{d t}+D z_{i}}{z_{i}}\left(N_{F T}-\left\langle N_{t}\right\rangle\right)
$$

where $D$ is the large-scale subsidence divergence, which is constant with height $\left(5 \times 10^{-6} \mathrm{~s}^{-1}\right)$. Previous studies that have applied similar approaches to observational data sets where large uncertainty exists in estimating the large-scale divergence have either attempted to constrain the subsidence and entrainment velocities from aerosol observations (e.g., the multilayer approach of Clarke et al. [1996]), assumed a fixed entrainment velocity [e.g., Van Dingenen et al., 1999], or neglected the large-scale subsidence divergence altogether [Hoell et al., 2000]. The turbulent transport term is positive when the concentration of free tropospheric $\mathrm{CCN}$ is greater than the MBL concentration, i.e., $N_{F T}>$ $\left\langle N_{t}\right\rangle$, in effect tapping the tropospheric CCN reservoir. When the term is negative, the MBL $N_{t}$ concentration can be reduced or "diluted" by entrainment. Both the increase and dilution of boundary layer $N_{t}$ have a basis in observation and are important physical processes.

[26] From COAMPS output and the turbulent transport term evaluated in equation (4), we can calculate and compare all the terms in the $\mathrm{CCN}$ budget. However, a small ( $1 \%$ in 12 hours) model numerical source of CCN, estimated from a sensitivity experiment in which collision-coalescence processes were turned off, is present. We attribute this artificial source to the relatively crude advection scheme (second-order centered difference) used in the model. For purposes of the analysis, this source was removed by way of a time-dependent correction determined from a simulation in which collision-coalescence processes were switched off and $N_{t}$ was in effect a passive tracer.

[27] Figure 5 shows normalized cloud processing, the fraction of the boundary layer mean reduction of $\left\langle N_{t}\right\rangle$ attributable to cloud processing. Of the significant reduction of $\left\langle N_{t}\right\rangle$ in simulation C800 (Figure 4f) at 12 hours, only $\sim 10 \%$ results from cloud processing, while entrainment dilution is responsible for the vast majority $(\sim 90 \%)$. The contribution of cloud processing to depletion becomes progressively more important as the ambient CCN concentration decreases; in the C100 simulation, for example, cloud processing is responsible for over $80 \%$ of the depletion at 12 hours. For larger initial values of $N_{C C N}$, cloud processing is slower to increase and removes a smaller fraction of the particles. This behavior is associated with higher $\mathrm{CCN}$ concentrations suppressing the collisioncoalescence process and the formation of drizzle [Albrecht, 1989], as evident in the relative difference in drizzle rates between the simulations (Figure $3 \mathrm{~d}$ ). In addition, the steep- 


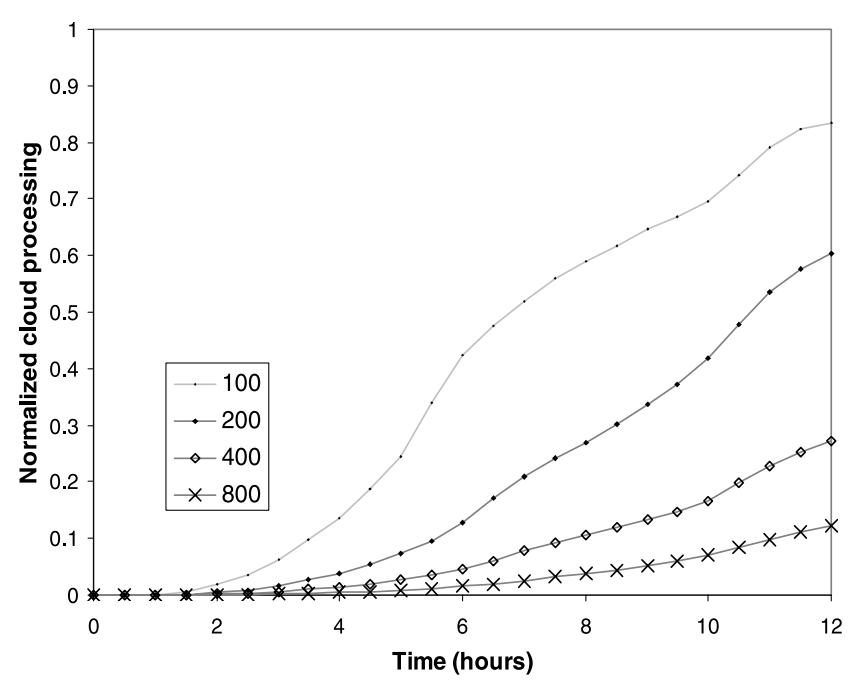

Figure 5. Time series of normalized cloud processing (the fraction of $\left\langle N_{t}\right\rangle$ reduction from cloud processing alone) for simulations C100, C200, C400, and C800.

ening of the processing curves in Figure 5 tends to be associated with the "pulses" in drizzle rates.

[28] Few past studies systematically evaluated the separate contributions from entrainment, cloud processing, advection, and source terms sufficiently to allow a robust comparison with our cloud processing rates. Using a $2 \mathrm{D}$ LES, Feingold et al. [1996] found a 25\% reduction in MBLmean CCN concentration after 3 hours for initial conditions similar to those in our simulations and an initial $\mathrm{CCN}$ concentration of $50 \mathrm{~cm}^{-3}$. A COAMPS simulation with the same initial $\mathrm{CCN}$ configuration (not shown) produces a 3 hour depletion of $30 \%$, in good agreement with the LES estimate of Feingold et al. Since the free tropospheric CCN concentration is $50 \mathrm{~cm}^{-3}$, in both cases these reductions include a slight entrainment source, with the implication that the reduction in number concentration due to cloud processing is actually larger in magnitude than the $25-30 \%$ values. How much larger? Given the free tropospheric concentration and a mean entrainment rate of $0.8 \mathrm{~cm} \mathrm{~s}^{-1}$, a simple calculation using equations (2) and (4) shows that the magnitude of the entrainment source term is only $\sim 10 \%$ of the observed $\mathrm{CCN}$ reduction; therefore we estimate that the actual depletion arising from cloud processing will be $\sim 28-33 \%$.

\subsection{Relative Contributions of Autoconversion and Accretion to Cloud Processing}

[29] The efficiency of drizzle production clearly depends on cloud droplet concentration, and in the case of our closely coupled aerosol-droplet system, on $N_{t}$. Since larger values of $N_{t}$ are associated with smaller fractional depletions (Figure 5), it is reasonable to expect that the cloud processing rate strongly depends on $N_{t}$ as well. For all simulations, the MBL-depletion rates calculated according to equation (2) increase with time until near the end of the simulations (Figure 6), although the rates increase more rapidly with time in the cleaner cases. However, counterintuitively, the same depletion rate can be associated with different values of total particle concentration $N_{t}$ (e.g., shaded line in Figure 6). For the KK parameterization, the time rate of change of $N_{c}$ is given by the right hand side of equation (35) in the work by Khairoutdinov and Kogan [2000], which assumes all the collected droplets have mean droplet radius $r_{v c}$,

$$
\frac{\partial N_{c}}{\partial t}=\frac{-\left.\frac{\partial q_{r}}{\partial t}\right|_{\text {auto }}-\left.\frac{\partial q_{r}}{\partial t}\right|_{\text {accretion }}}{\left(\frac{4 \pi \rho_{w}}{3 \rho_{a}} r_{v c}^{3}\right)}
$$

where $\rho_{w}$ and $\rho_{a}$ are the density of water and air, respectively. The expression for $r_{v c}$ based on the two moments is

$$
r_{v c}=\left(\frac{3 \rho_{a}}{4 \pi \rho_{w}}\right)^{1 / 3} q_{c}^{1 / 3} N_{c}^{-1 / 3}
$$

Substituting the expressions for autoconversion, accretion, and mean volume radius, into equation (5) gives

$$
\frac{\partial N_{c}}{\partial t}=\frac{-a q_{c}^{b} N_{c}^{c}-e\left(q_{c} q_{r}\right)^{f}}{q_{c} / N_{c}}=-a q_{c}^{b-1} N_{c}^{c+1}-e N_{c} q_{c}^{f-1} q_{r}^{f},
$$

where the parameters $a, b, c, e$, and $f$ are $1350,2.47,-1.79$, 67 , and 1.15 , respectively. Wood [2005b] compares the rate of loss of cloud droplets predicted by equation (7) with that from the stochastic collection equation, computed using spectra from twelve different research flights. The bulk parameterization is generally in good agreement (his Figure 7a), especially for larger values of depletion, though it slightly overestimates smaller values. Furthermore, the strong agreement implies that little error is introduced by assuming that the coalescence scavenging is distributed among droplets of constant radius $r_{v c}$. Cloud processing in COAMPS proceeds according to equation (7), although for Figure 5 we obtain it from the budget residual in equation (2). The two methods are within a few percent of each other.

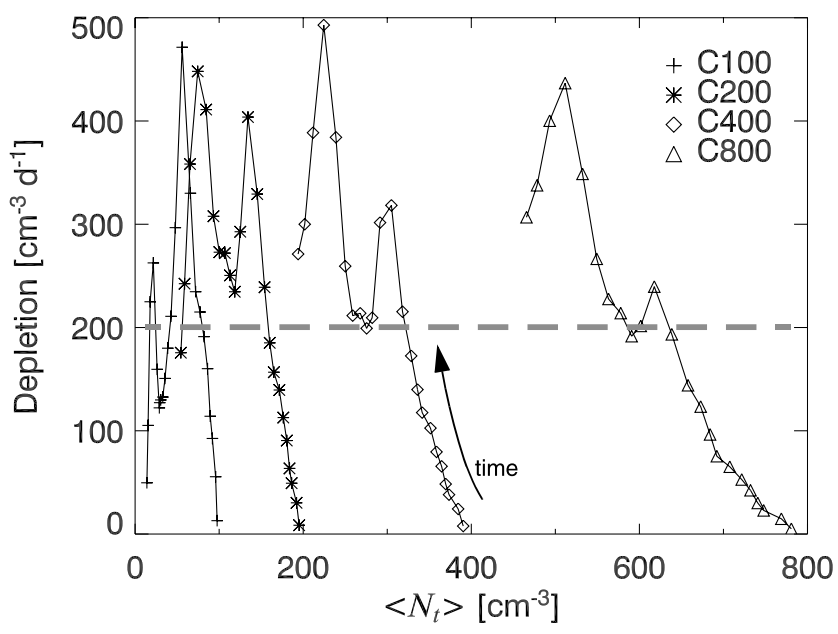

Figure 6. Depletion rate from cloud processing as a function of $\left\langle N_{t}\right\rangle$ for the four baseline simulations. Time runs from $t=1$ hour at the bottom of the lines, upward, with symbols spaced at $30 \mathrm{~min}$ intervals. Shaded dashed line represents an equivalent value of depletion for each simulation. 

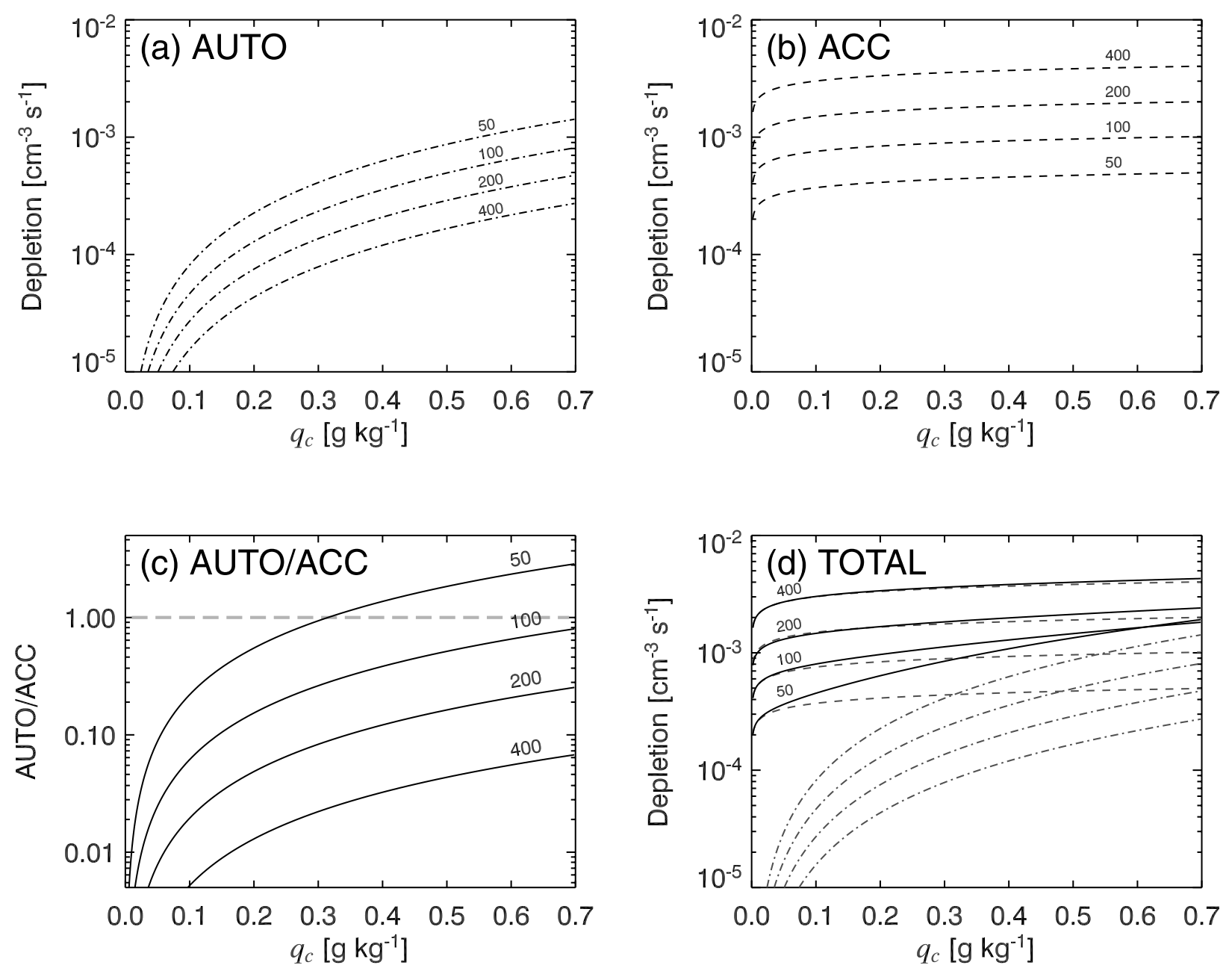

Figure 7. Depletion of cloud droplet concentration from collision-coalescence for specified cloud number concentrations. Drizzle water mixing ratio is assumed for the accretion calculation to be $0.003 \mathrm{~g} \mathrm{~kg}^{-1}$. (a) Autoconversion, (b) accretion, (c) ratio of depletions from autoconversion and accretion, and (d) total depletion.

[30] As evident by equation (7) and Figure 7, both autoconversion and accretion contribute to depletion. In the calculations for Figure 7, drizzle water content $\left(q_{r}\right)$ was assumed to be $0.003 \mathrm{~g} \mathrm{~kg}^{-1}$. In reality $q_{r}$ is highly variable and will in fact depend on autoconversion. The particular value chosen is the modal drizzle water content at 6 hours for the $\mathrm{C} 400$ simulation, though any reasonable magnitude of $q_{r}$ will satisfy to demonstrate the possibility that widely varying droplet concentrations can result in similar depletion rates. Accretion tends to be the dominant depletion mechanism over values of $q_{c}$ and $N_{c}$ typical of stratocumulus (Figures $7 \mathrm{~b}$ and $7 \mathrm{c}$ ). This result for depletion is analogous to the conclusion of Wood [2005b], who argues that accretion is the dominant process responsible for drizzle water production, and therefore cloudwater loss (which is the key to removal of $\mathrm{CCN}$ ). For certain combinations of $q_{c}$, $q_{r}$, and $N_{c}$, however, the contributions of autoconversion and accretion to depletion can become comparable. Autoconversion becomes more important as a depletion mechanism as $q_{c}$ increases and $N_{c}$ decreases (Figures $7 \mathrm{a}$ and $7 \mathrm{c}$ ).

[31] The autoconversion and accretion terms vary as a function of $q_{c}$ and $N_{c}$ in such a way that the sum can sometimes be invariant on $N_{c}$ (Figure 7d). Mathematically, the possibility of the two terms being of similar magnitudes makes sense, since the loss in concentration from autoconversion is proportional to $N_{c}^{-0.79}$, while the loss from accretion is proportional to $N_{c}$. This inversely varying relationship makes possible the invariance on $N_{c}$ suggested in Figure $7 \mathrm{~d}$ and is one explanation for similar values of depletion being associated with different total particle concentrations in Figure 6.

[32] In order to understand more clearly the conditions under which the four " $\mathrm{C}$ " simulations might exhibit the same depletion rate, we explore the behavior of equation (7), constrained by a depletion rate of $200 \mathrm{~cm}^{-3} \mathrm{~d}^{-1}$ (represented by the shaded line in Figure 6). The parameter space is represented in Figure 8 by contours of $q_{r}$ as a function of $N_{t}$ and $q_{c}$. The predominantly vertical slope of the $q_{r}$ contours over much of the parameter space implies that the existence of equivalent depletion rates under different ambient $\mathrm{CCN}$ concentrations (i.e., different values of $N_{t}$ ) likely cannot be explained by a difference in $q_{c}$ alone. Cloud system behavior in simulations C100, C200, C400, and C800, moreover, confirms this notion. Values of cloud-mean $N_{t}$ 


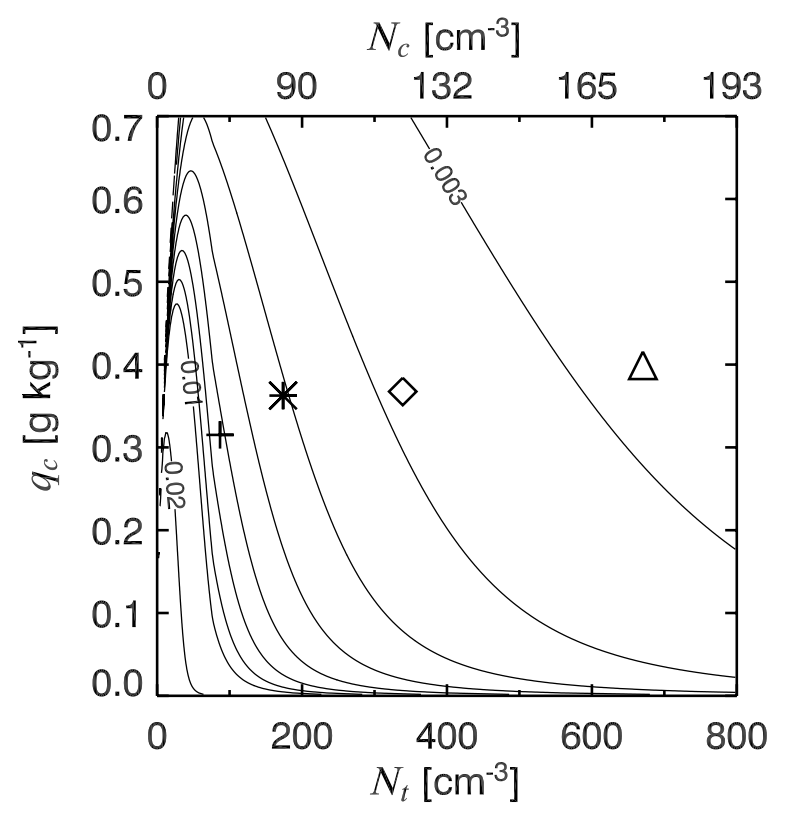

Figure 8. Parameter space of $N_{\mathrm{t}}, q_{\mathrm{c}}$, and $q_{\mathrm{r}}$, given the depletion rate denoted by the shaded dashed line on Figure 6. Contours represent the $q_{\mathrm{r}}\left(\mathrm{g} \mathrm{kg}^{-1}\right)$ required to satisfy equation (7) for a depletion rate of $200 \mathrm{~cm}^{-3} \mathrm{~d}^{-1}$ at the specified values of $N_{\mathrm{t}}$ and $q_{\mathrm{c}} . N_{\mathrm{c}}$ values along the top axis are obtained from the nucleation parameterization. Contour interval is $0.001 \mathrm{~g} \mathrm{~kg}^{-1}$, except for the highest contour level, which has magnitude $0.02 \mathrm{~g} \mathrm{~kg}^{-1}$. Symbols are representative values from $\mathrm{C} 100, \mathrm{C} 200, \mathrm{C} 400$, and C800 (left to right) which correspond to a depletion rate of $200 \mathrm{~cm}^{-3} \mathrm{~d}^{-1}$.

and $q_{c}$ for selected times in each simulation when the cloud-mean depletion rate was $200 \mathrm{~cm}^{-3} \mathrm{~d}^{-1}$ are plotted on Figure 8. Here the cloud-mean values of $q_{c}$, which roughly represent $q_{c}$ in the middle of the cloud, vary only between $0.3-0.4 \mathrm{~g} \mathrm{~kg}^{-1}$ in all four cases. Therefore only significant differences in $q_{r}$ can produce equivalent depletion rates in the four cases. These significant differences in $q_{r}$ between simulations seem plausible, moreover, since drizzle amount is inversely related to $N_{t}$. Physically speaking, this result is an indication that depletion is strongly tied to drizzle production. Because the contours are not exactly vertical, for some regions of the parameter space a large difference in $q_{c}$ between the simulations could conceivably bring about the same processing rate; however, the required difference in $q_{c}$ would be implausibly large, much larger than typically produced in these simulations. This strong dependence on $q_{r}$ weakens somewhat at large values of $N_{t}$ and breaks down altogether near values of $30 \mathrm{~cm}^{-3}$.

\subsection{Scalings for Depletion and Drizzle}

[33] The result that depletion is largely independent of $N_{t}$, at least for experiments $\mathrm{C} 100-\mathrm{C} 800$, enables the unique relationship between drizzle rate and depletion in Figure 9 that is not directly dependent on droplet concentration. In Figure 9, depletion is calculated from instantaneous values according to equation (7) as a mean over all cloudy points $\left(N_{c}>1 \mathrm{~cm}^{-3}\right)$ and then multiplied by $\left(z_{i}-z_{b}\right) / z_{i}\left(z_{i}\right.$ and $z_{b}$ are mean cloud base and inversion height, respectively, obtained from the averaging methodology described in section 3.1) to scale the rate over the MBL. As stated in section 3.3, independent calculations of MBL-mean depletion from equations (7) and (2) are within a few percent of each other. Mean cloud base drizzle rate was defined in section 3.1 and is taken as an average over the entire (horizontal) domain, not just conditionally sampled over cloudy columns. Both quantities are instantaneous and calculated using half-hour COAMPS data output. Figure 9 suggests two depletion regimes for the COAMPS simulation results. In the first regime, the depletion rate depends on drizzle intensity, not on ambient CCN concentration. For drizzle rates less than $0.6 \mathrm{~mm} \mathrm{~d}^{-1}$, the dependence on drizzle rate may be represented by a simple power law of

$$
D=325 R^{0.581}
$$

where $D$ is $\mathrm{cm}^{-3} \mathrm{~d}^{-1}$ and $R$ is drizzle rate in $\mathrm{mm} \mathrm{d}^{-1}$, and describes depletion as a function of cloud base drizzle rate generally within a factor of two $\left(r^{2}=0.93\right)$. This simple relationship is chiefly applicable for small resolved vertical motions and holds until near the end of the simulations when the small values of $N_{t}$ in cloudy regions appear to limit depletion. This second depletion regime is represented in Figure 9 by the points with drizzle rates greater than about $0.6 \mathrm{~mm} \mathrm{~d}^{-1}$ that lie off the power law curve. The power law for all points is $D=248 R^{0.464}$, with $r^{2}=0.71$. Similar power laws exist for surface drizzle rate, with larger coefficients arising from the evaporation of drizzle falling through the subcloud layer. The possibility of drizzle evaporation in the subcloud layers of various depths and relative humidities increases the error in the surface drizzle relationship, to the point where it becomes meaningless for drizzle that completely evaporates before reaching the ground. Both relationships show little sensitivity to the particular value of initial $N_{t}$, except perhaps in the second, limiting regime when $N_{t}$ becomes very small (less than about 60 ).

[34] A theoretical estimate of MBL-mean depletion from drizzle rate according to Albrecht [1989] for a cloud thickness of $400 \mathrm{~m}$ lies within the span of the COAMPS results in Figure 9. Hoell et al. [2000] calculated a rate of loss due to precipitation during the ACE-2 (North Atlantic Regional Aerosol Characterization Experiment) project and estimated an accumulation mode depletion rate of $144 \mathrm{~cm}^{-3} \mathrm{~d}^{-1}$ over a 2 hour drizzle event for an initial value of $670 \mathrm{~cm}^{-3}$. ON the basis of in situ aircraft observations at cloud base for the same case, Osborne et al. [2000] estimated cloud base precipitation rate for this period of about $0.04 \mathrm{~mm} \mathrm{~d}^{-1}$. The depletion, scaled over the boundary layer depth, from these two combined sources in Figure 9 is greater than COAMPS depletion for the given drizzle rates, although caution is in order when combining calculations from two largely independent studies.

[35] A large eddy simulation of case C200 was analyzed in order to compare cloud processing rates with those from COAMPS. The LES model is based on 3D Boussinesq dynamics and explicitly represents the turbulent boundary layer eddies, which are for the most part parameterized in the mesoscale model. Size-resolved cloud physics processes are formulated on the basis of prognostic equations for $19 \mathrm{CCN}$ and $25 \mathrm{cloud} /$ drizzle droplet bins. The LES is 


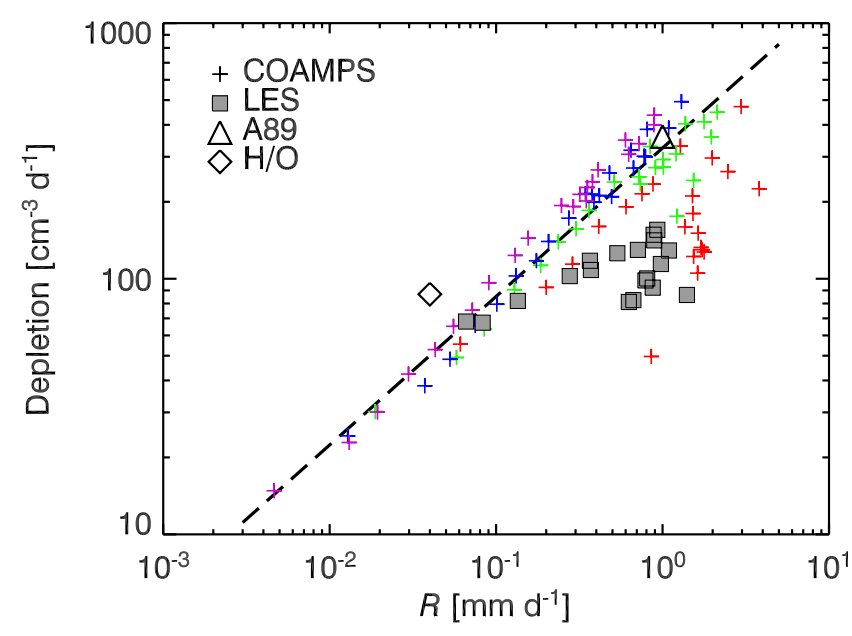

Figure 9. MBL-mean depletion as a function of cloud base drizzle rate for the four baseline COAMPS simulations (crosses) and the LES simulation (solid rectangles). COAMPS results are stratified by color: $\mathrm{C} 100$ (red), C200 (green), C400 (blue), and C800 (magenta). The triangle represents a theoretical calculation as in the work by Albrecht [1989] for a cloud thickness of $400 \mathrm{~m}$. The diamond denoted by $\mathrm{H} / \mathrm{O}$ represents a synthesis of results by Hoell et al. [2000] and Osborne et al. [2000]. Dashed line is the power law fit represented by equation (8). See the text for more details.

described in detail by Kogan [1991], Kogan et al. [1995], and Khairoutdinov and Kogan [1999]. The model has been extensively verified against aircraft observations [Khairoutdinov and Kogan, 1999; Liu et al., 2000], and indirect tests of a bulk drizzle parameterization derived from model drop size distributions (the KK parameterization) showed good agreement with in situ aircraft data [Wood, 2005b].

[36] The LES is initialized with ASTEX A209 conditions, the same as those used for the COAMPS simulations. The initial aerosol configuration is intended to be similar to C200 and assumes a lognormal distribution with modal radius $0.05 \mu \mathrm{m}$, width parameter $(\sigma)$ of $1.5 \mu \mathrm{m}$, and total MBL concentration of $200 \mathrm{~cm}^{-3}$. As in C200, the free tropospheric concentration is zero. We do not go into detail about the LES results but only concentrate on calculations of cloud processing for comparison with COAMPS. Cloud processing (depletion) in the LES is calculated directly on the basis of the coagulation process and is averaged over 30 min periods (2-3 eddy turnover cycles). For given drizzle rates $(R)$, LES depletion rates in Figure 9 are generally lower (from $1 / 2-2 / 3$ smaller) than the corresponding rates from the COAMPS simulations.

[37] The single parameter formula in equation (8) fits the COAMPS simulations for drizzle rates less than $0.6 \mathrm{~mm} \mathrm{~d}^{-1}$ but degrades at larger values of $R$. From an analytical development beginning with the stochastic collection equation, Wood [2006] suggests a formulation of depletion based on the product of droplet concentration and drizzle rate $\left(N_{c} R\right)$. Our COAMPS and LES results plotted in Figure 10 against this new scaling demonstrate improved correlation relative to the 1 parameter relation, especially for larger values of depletion. The exponent of the best fit to the COAMPS results differs somewhat from Wood's linear scaling:

$$
D=69.4\left(N_{c} R\right)^{0.668} .
$$

In equation (9), $N_{c}$ and $R$ are expressed as $\mathrm{cm}^{-3}$ and $\mathrm{cm} \mathrm{d}^{-1}$, respectively, to be consistent with the horizontal axis on Figure 10.

[38] Given the $2 \mathrm{~km}$ horizontal grid spacing in the mesoscale model, the turbulent eddies which in nature drive the precipitation process are only partially resolved, leaving the SGS to represent the bulk of the MBL dynamics. How reasonable, then, are the resulting precipitation amount and behavior? Recently, much research has centered on exploring scalings for drizzle based on fundamental cloud properties. These observationally based relationships are potentially very important for parameterizing drizzle rate and cloud droplet depletion in large-scale models, and it is natural to investigate how they compare to the bulk properties of cloud and drizzle in COAMPS. Pawloska and Brenguier [2003] found that drizzle rate scaled as $H^{4} N^{-1}$, where $H$ and $N$ are cloud depth and mean droplet concentration, respectively. Drizzle rate scaled as $(L W P / N)^{1.75}$ in an observational study of subtropical eastern Pacific marine stratocumulus [Comstock et al., 2004]. VanZanten et al. [2005] showed that cloud base drizzle rate from seven research flights during the Dynamics and Chemistry of Marine Stratocumulus (DYCOMS-II) project generally scaled with $H^{3} N^{-1}$. Wood [2005a] contains a summary comparison of these drizzle rate scalings. Half-hourly COAMPS results from the four " $C$ " simulations fit the DYCOMS-II $H^{3} N^{-1}$ scaling fairly (Figure 11a) and behave similarly for the $(L W P / N)^{1.75}$ scaling (not shown). COAMPS behavior seems to be described best by a

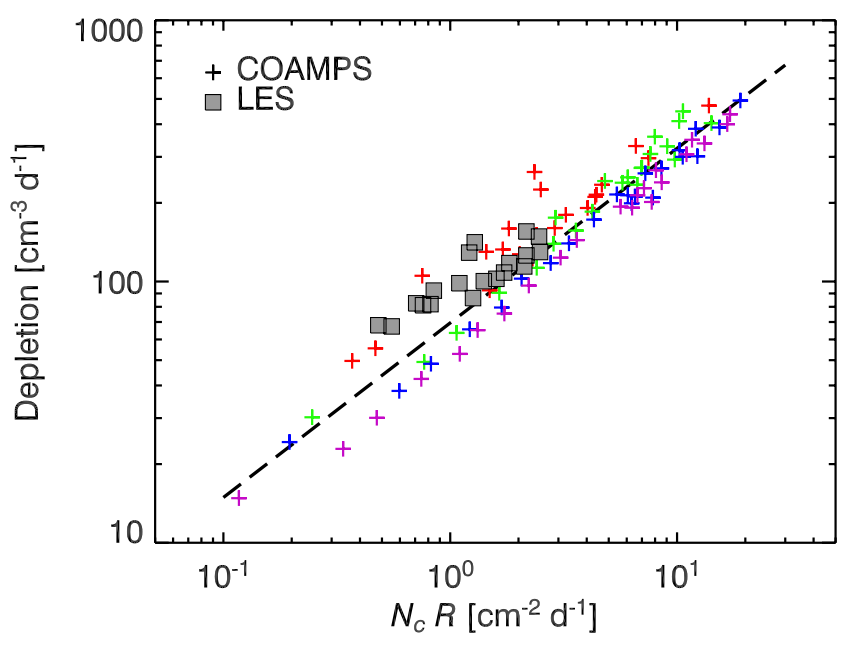

Figure 10. Alternate scaling for MBL-mean depletion suggested by Wood [2006] for the four baseline COAMPS simulations (crosses) and the LES simulation (solid rectangles). Crosses are colored to indicate $\mathrm{C} 100$ (red), C200 (green), C400 (blue), and C800 (magenta) simulations. 

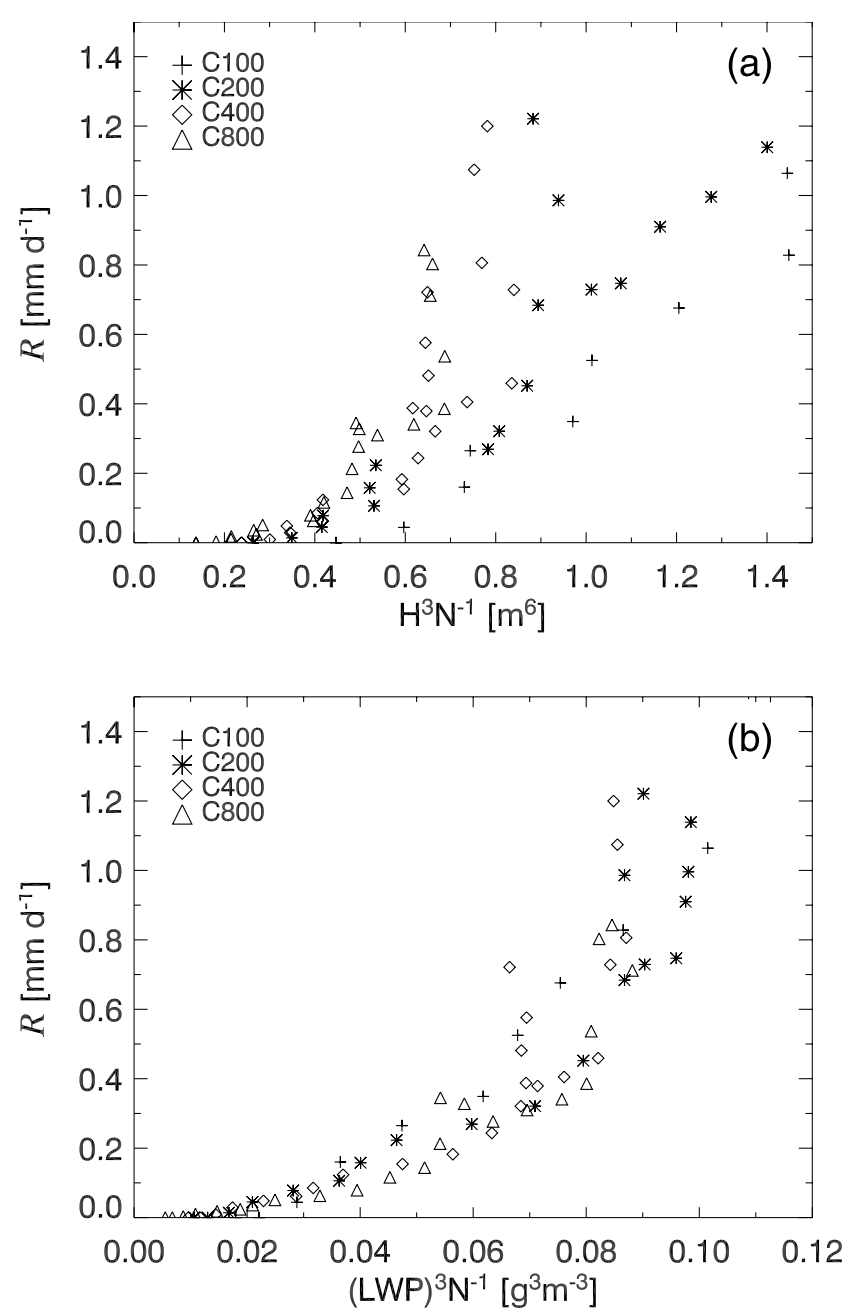

Figure 11. Two scalings for cloud base drizzle rate. (a) $H^{3} N^{-1}$ and (b) $(L W P)^{3} N^{-1}$.

physically similar scaling of $(L W P)^{3} N^{-1}$ (Figure 11b). Both drizzle rate scalings show indications of the two depletion regimes visible in Figure 9, stratified according to a drizzle rate of about $0.6 \mathrm{~mm} \mathrm{~d}^{-1}$.

\section{Sensitivity of Cloud Processing to CCN Sources}

[39] The previous discussion of cloud processing neglected fundamental CCN sources that aid in maintaining adequate nucleation sites for subsequent boundary layer cloud cycles. We perform sensitivity experiments to test the importance of various CCN source configurations and rates relative to cloud processing. The experimental configurations are based on knowledge or current hypotheses of boundary layer $\mathrm{CCN}$ source mechanisms, specifically what we term the entrainment source and local (in situ or surface) sources. For these experiments, the initial value of $N_{C C N}$ in the boundary layer was set to $200 \mathrm{~cm}^{-3}$.

\subsection{Entrainment Source}

[40] The free troposphere supplies a common source of $\mathrm{CCN}$ as the boundary later entrains. Numerous studies, such as Hoell et al. [2000] and Osborne et al. [2000], have examined the behavior of $\mathrm{CCN}$ and cite dilution/entrain- ment as the dominant mechanism for change. Dilution is a special case of entrainment when the free tropospheric concentration is less than that of the boundary layer. At times the entrained air is much more polluted than the boundary layer air (e.g., simulations by Jiang et al. [2002], based on an ASTEX case different from ours) and supplies a significant source of boundary layer CCN. Several mechanisms have been postulated for the source of this elevated polluted layer. Raes [1995] argued that it derives fundamentally from the downward branches of Hadley circulation over the subtropics. Other studies [e.g., Garrett and Hobbs, 1995] have implied that horizontal transport of polluted, continental air masses is responsible, although the generally barotropic nature of the subtropical high would preclude this mechanism as a $\mathrm{CCN}$ source for (clean) oceanic boundary layers.

[41] Simulations E0-E800 demonstrate the importance of the entrainment source in influencing the mean boundary layer $\mathrm{CCN}$ concentration. Free tropospheric conditions in these simulations range from zero to $800 \mathrm{~cm}^{-3}$, all of which are less than the value of $1200 \mathrm{~cm}^{-3}$ used by Jiang et al. [2002]. For a free tropospheric concentration greater than about $400 \mathrm{~cm}^{-3}$, the entrainment source more than offsets depletion due to all causes, as indicated in Figure 12a. When entrained into the MBL, free tropospheric CCN counteract depletion from cloud processing (Figure 12a) and suppress drizzle (Figure 12b). Of course, from equation (3), the entrainment source is dependent not only upon the difference between the MBL and free tropospheric concentration but also on the entrainment rate. A reduction in entrainment rate, for example from weaker cloud top cooling accompanying a decrease in LWC, will reduce the entrainment source. The entrainment sensitivity experiments exhibit power law relationships between drizzle rate
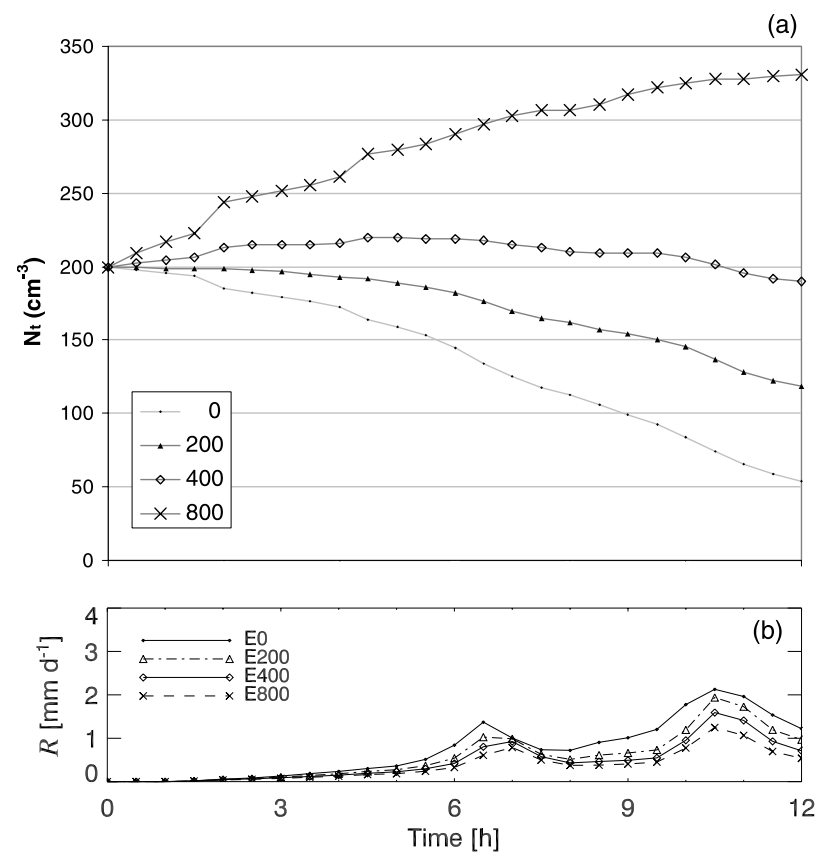

Figure 12. Time series for the entrainment source experiments E0, E200, E400, and E800. (a) $\left\langle N_{t}\right\rangle$ and (b) cloud base drizzle rate. Simulation E0 is identical to C200. 

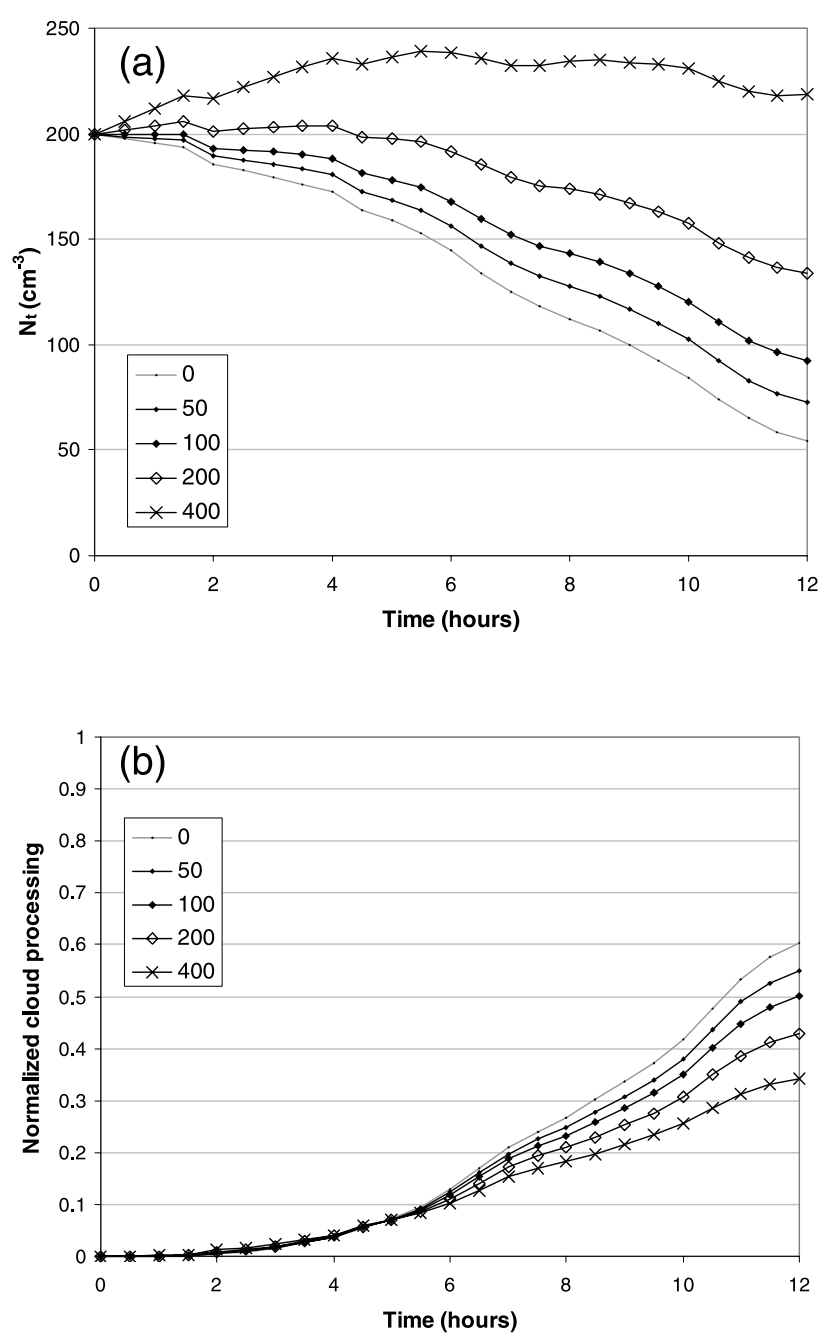

Figure 13. (a) Evolution of $\left\langle N_{t}\right\rangle$ for the in situ source experiments S0, S50, S100, S200, and S400. Values correspond to concentration of $\mathrm{CCN}$ added per day. Simulation S0 is identical to C200. (b) Normalized cloud processing, as in Figure 5, but for the S-series simulations.

and cloud processing (not shown) similar to the control simulations.

\subsection{In Situ MBL and Surface Sources}

[42] Certain CCN source mechanisms are best represented by boundary-layer-wide sources. For example, enlargement of $\mathrm{CCN}$ via heterogeneous chemical reactions to a size large enough to be activated is known to occur within clouds [O'Dowd et al., 1997; Hoell et al., 2000] and is best represented in a MBL-mean sense. For numerical models that parameterize vertical transport, injection of sea salt by rough seas and subsequent mixing in the vertical may be best represented this way, especially if the time step is larger than the characteristic eddy turnover time (as unlikely as this may be in a mesoscale model setting). The sea salt source may be particularly important, considering the high activity of large salt particles relative to smaller sulfate particles [O'Dowd et al., 1997], and is a strong function of wind speed. For a typical MBL of depth $800 \mathrm{~m}$, the sea salt source becomes significant at speeds greater than about $10 \mathrm{~m} \mathrm{~s}^{-1}$ [Hoell et al., 2000].

[43] The "S" suite of experiments is similar to C200 but with various $\mathrm{CCN}$ source rates within the boundary layer. The source rates are specified in terms of concentration added per day, and are added every timestep of the simulations. An in situ source of $\sim 350 \mathrm{~cm}^{-3} \mathrm{~d}^{-1}$ would be required to offset the loss from cloud processing and to maintain the mean MBL CCN concentration at $200 \mathrm{~cm}^{-3}$ (Figure 13a). As expected, adding $\mathrm{CCN}$ at a greater rate suppresses cloud processing (Figure 13b).

[44] Are any presently identifiable in situ or surface sources of this large magnitude comparable to the cloud processing rates in our study? For an MBL-mean source to be able to offset a cloud depletion of $\sim 350 \mathrm{~cm}^{-3} \mathrm{~d}^{-1}$ seems unlikely. Raes [1995] argued that CCN (0.3\%) production via heterogeneous chemistry occurs over timescales greater than three days, considerably longer than typical MBL timescales. Other modeling studies, however, have demonstrated that under certain conditions heterogeneous chemistry can influence MBL cloud behavior [Feingold et al., 1996; Feingold and Kreidenweis, 2002]. They found that the conversion of $\mathrm{SO}_{2}$ to sulfate to be of similar magnitude to cloud processing under conditions of low liquid water content, while cloud processing dominates at higher liquid water content and when spectra broaden upon multiple cloud cycling events. The impact of aqueous chemistry, on the other hand, decreases as the atmospheric reagents are consumed. It is important to note that these chemical processes do not actually increase total particle number concentration; rather, they increase particle size and hence make them more easily activated. For this reason, prior studies have not framed the chemical processes in terms of bulk CCN source rates. It seems reasonable, however, to treat this chemistry as a CCN source, as particles traverse an arbitrary size/supersaturation threshold, although the complexities of parameterizing this process in a bulk model are challenging.

[45] Although the MBL concentrations of micron and larger sea salt particles are small relative to sulfate concentrations, flux from the ocean can enhance the concentration of smaller submicron aerosol as well [O'Dowd et al., 1997]. Hoell et al. [2000] estimated MBL submicron sea salt source rates of $99 \mathrm{~cm}^{-3} \mathrm{~d}^{-1}$ and $10 \mathrm{~cm}^{-3} \mathrm{~d}^{-1}$ in a highly polluted and a clean environment, respectively. Although these rates are less than typical cloud processing rates, they nevertheless can contribute appreciably to the MBL budget. However, a single bulk CCN concentration is not able to represent the enhanced hygroscopy of the micron size particles.

\section{Discussion and Conclusions}

[46] Quality mesoscale forecasts require accurate representations of source/sink process rates, in addition to specification of initial and boundary conditions. Sea salt sources are parameterizable as a function of surface wind speed, while at least currently (in our opinion) accounting for heterogeneous chemical processes is beyond the ability of simple bulk models. Quantifying the entrainment source from the free troposphere requires knowledge of the vertical 
CCN distribution and the ability to accurately diagnose entrainment.

[47] Unfortunately, routine $\mathrm{CCN}$ measurements are not a standard component of meteorological data collection. Satellite remote sensing is one method for obtaining these measurements [e.g., Mishchenko et al., 1997], although such techniques frequently have limitations such as being restricted to daytime or only giving a vertically integrated measurement. Other methods utilize combinations of surface measurements and remote sensing [e.g., Feingold et al., 1998; Ghan and Collins, 2004], though these are fundamentally local in nature and require suites of expensive instruments. A more realistic manner of supplying initial and boundary conditions for $\mathrm{CCN}$ concentration is required. Because of the requirement for three-dimensional initialization fields, global chemistry models [e.g., Chin et al., 2000] may be the best candidate.

[48] We have run a mesoscale model in an idealized configuration to evaluate the relative importance of cloud processing (collision-coalescence) and various physically based sources to an MBL CCN budget in order to evaluate the parameters required for an accurate forecast. The model uses a 2-moment microphysical parameterization and contains a prognostic equation for bulk CCN concentration. Cloud processing obtained from a residual of the $\mathrm{MBL}$ $\mathrm{CCN}$ budget is consistent with that calculated directly from the KK parameterization. Our results demonstrate that COAMPS cloud processing rates are in good agreement with LES and observational estimates. The MBL cloud properties behave predictably under different initial concentrations of $\mathrm{CCN}$, with smaller values associated with stronger drizzle, smaller cloud LWC, and suppressed entrainment. All of the control cases, in which $\mathrm{CCN}$ is initialized only in the MBL, exhibit a decrease of $\mathrm{CCN}$ concentration over the 12 hour simulation period. The reduction is accomplished predominantly by entrainment dilution in the polluted case and by cloud processing in the clean case.

[49] Counterintuitively, cloud processing rate is not directly dependent upon total particle concentration; specifically, cloud processing rates are not uniquely associated with values of total concentration $\left\langle N_{t}\right\rangle$. We evaluated relative contributions to the processing rates from autoconversion and accretion in the microphysics scheme to explore this behavior. The droplet loss from autoconversion is proportional to $N_{c}^{-0.79}$, while loss from accretion is proportional to $N_{c}$. This inverse relationship is the most important factor in explaining the invariance on $N_{c}$ (and thus on $\left\langle N_{t}\right\rangle$ ). Depletion from accretion tends to dominate for higher droplet concentrations, while at lower concentrations, or for smaller values of drizzle water content, depletion from autoconversion can be of the same magnitude.

[50] Instead of dependence on $\left\langle N_{t}\right\rangle$, we find a robust relationship between cloud processing and combinations of drizzle rate and droplet concentration. For low to moderate drizzle rates $\left(R<0.6 \mathrm{~mm} \mathrm{~d}^{-1}\right)$, a power law describes the dependence of COAMPS cloud processing on drizzle intensity. The power law is most applicable for weak resolved updrafts and breaks down at large drizzle rates, when rapidly decreasing values of $N_{t}$ in regions of resolved vertical motion appear to limit depletion. Similar behavior exists for surface drizzle rate, though the relationship is more complex because of evaporation in the subcloud layer. A scaling for cloud processing based on drizzle rate and droplet concentration similar to that derived analytically by Wood [2006] vastly improves the fit over a broader range of drizzle rates. Our two parameter depletion scaling better fits results from LES with size-resolving microphysics.

[51] The one parameter power law relationship in equation (8) might form the basis of prescribing cloud processing for drizzle rates in a numerical model (cloud, mesoscale, or GCM) that does not keep track of droplet concentration independently as part of its microphysical scheme. This approach would apply to large-scale models that employ single moment (water content only) microphysics schemes but that still attempt to include aerosol. Including information about droplet concentration (equation (9)) would result in more accurately prescribed cloud processing for larger drizzle rates where depletion rates become much more significant. As more models employ multiplemoment microphysical schemes, it will become natural to develop expressions for cloud processing rates similar to equation (7). We also speculate that equations (8) and (9) could be used to diagnose cloud processing rates from cloud base drizzle rates estimated from radar data using $Z-R$ relationships [e.g., Vali et al., 1998; Comstock et al., 2004], along with estimates of droplet concentration (required for equation (9)).

[52] Sensitivity experiments demonstrate the relative importance of in situ, surface, and entrainment sources. The entrainment source is of greatest importance relative to cloud processing and encompasses both dilution and enhancement of $\mathrm{CCN}$ by tapping into the free tropospheric reservoir. Accurately representing this source necessitates an accurate measure of the free tropospheric CCN and a realistic entrainment rate. Although beyond the scope of this study, improving the representation of cloud-top entrainment rates in models is a common topic of investigation, and we expect continual improvement along those lines. In our experience, COAMPS entrainment rates seem reasonable for this case and others.

[53] The in situ source experiments represent the effects of heterogeneous chemical processes and flux of sea salt nuclei from ocean spray. Although some past studies have demonstrated that heterogeneous chemistry can influence MBL cloud structure, the magnitude of the source rate required to balance cloud processing is implausibly large, especially over subsequent cloud cycles as the collisioncoalescence process becomes more efficient and reagents for the chemical processes become scarce. Furthermore, parameterizing this process in a bulk microphysical setting is a challenging problem. Depending upon the wind conditions, surface sources of submicron sea salt are significant but nevertheless still less than the loss of particles from highly depleting cloud systems. These submicron size salt particles are only moderately more hygroscopic than sulfate nuclei of similar size and compose a measurable source to the MBL budget. The larger, micron size particles that can serve as drizzle nuclei are much rarer and are not represented by our bulk CCN parameter. Parameterizations exist that specify sea salt flux as a function of wind speed, although they are a function of size, which poses a problem when representing $\mathrm{CCN}$ by a single bulk quantity. 
[54] Our results show that cloud processing and entrainment effects (dilution or tapping the reservoir) dominate the MBL budget, which leads to the following possibility. If from remote sensing techniques or global chemistry models it is possible to obtain a representative free tropospheric value of $\mathrm{CCN}$, or better yet the vertical profile of $\mathrm{CCN}$, and assuming reasonable model entrainment rates, the $\mathrm{CCN}$ entrainment source term will be represented in the model. In a mesoscale simulation that is typically 6-48 hours long, a remotely sensed $\mathrm{CCN}$ profile, or a profile calculated in a large-scale chemistry model, would presumably become part of the reanalysis/update cycle. Incorporating these observations into the update cycle would reduce the importance of having highly accurate local representations of the secondary source rates (e.g., chemistry). For the purposes of forecasting, incorporating accurate estimates of free tropospheric aerosol concentration into model analysis cycles would be more important than highly constrained local $\mathrm{CCN}$ source rates.

[55] Acknowledgments. The authors are grateful to Robert Wood for his thoughtful review and many helpful discussions pertaining to the cloud processing scalings in section 3.4. Suggestions from an anonymous reviewer made the methodology much more thorough and self-contained. COAMPS is a registered trademark of the Naval Research Laboratory. This research was supported by ONR grants N00014-05-1-0550 and N0001403-1-0304 and by the Office of Science (BER), U.S. Department of Energy, grant DE-FG02-05ER64062.

\section{References}

Ackerman, A. S., M. P. Kirkpatrick, D. E. Stevens, and O. B. Toon (2004), The impact of humidity above stratiform clouds on indirect aerosol climate forcing, Nature, 432, 1014-1017.

Albrecht, B. A. (1989), Aerosols, cloud microphysics, and fractional cloudiness, Science, 245, 1227-1230.

Chin, M., R. B. Rood, S.-J. Lin, J.-F. Müller, and A. M. Thompson (2000), Atmospheric sulfur cycle simulated in the global model GOCART: Model description and global properties, J. Geophys. Res., 105, 24,67124,687 .

Clarke, A. D., T. Uehara, and J. N. Porter (1996), Lagrangian evolution of an aerosol column during the Atlantic Stratocumulus Transition Experiment, J. Geophys. Res., 101, 4351-4362.

Comstock, K. K., R. Wood, S. E. Yuter, and C. S. Bretherton (2004), Reflectivity and rain rate in and below drizzling stratocumulus, Q. J. R. Meteorol. Soc., 130, 2891-2918.

Duynkerke, P. G., H. Zhang, and P. J. Jonker (1995), Microphysical and turbulent structure of nocturnal stratocumulus as observed during ASTEX, J. Atmos. Sci., 52, 2763-2777.

Feingold, G., and S. M. Kreidenweis (2002), Cloud processing of aerosol as modeled by a large eddy simulation with coupled microphysics and aqueous chemistry, J. Geophys. Res., 107(D23), 4687, doi:10.1029/ 2002JD002054.

Feingold, G., S. M. Kreidenweis, B. Stevens, and W. R. Cotton (1996), Numerical simulations of stratocumulus processing of cloud condensation nuclei through collision-coalescence, J. Geophys. Res., 101, $21,391-21,402$.

Feingold, G., S. Yang, R. M. Hardesty, and W. R. Cotton (1998), Feasibility of retrieving cloud condensation nucleus properties from Doppler cloud radar, microwave radiometer, and lidar, J. Atmos. Oceanic Technol., 15, $1188-1195$

Fiedler, B. H., and M. Khairoutdinov (1994), Cell broadening in threedimensional thermal convection between poorly conducting boundaries: Large eddy simulations, Beitr. Phys. Atmos., 67, 235-241.

Fiedler, B. H., and F. Kong (2003), The performance of an $E-l$ scheme for the atmospheric boundary layer in a mesoscale model with grid spacing as small as $1 \mathrm{~km}$, Meteorol. Atmos. Phys., 84, 1-10, doi:10.1007/s00703002-0574-6.

Flossmann, A. I., W. D. Hall, and H. R. Pruppacher (1985), A theoretical study of the wet removal of atmospheric pollutants. Part I: The redistribution of aerosol particles captured through nucleation and impact scavenging by growing cloud drops, J. Atmos. Sci., 42, $583-606$.
Garrett, T. J., and P. V. Hobbs (1995), Long-range transport of continental aerosols over the Atlantic ocean and their effects on cloud structures, J. Atmos. Sci., 52, 2977-2984.

Ghan, S. J., and D. R. Collins (2004), Use of in situ data to test a Raman lidar-based cloud condensation nuclei remote sensing method, J. Atmos. Oceanic Technol., 21, 387-394.

Harshvardhan, , R. Davies, D. Randall, and T. Corsetti (1987), A fast radiation parameterization for atmospheric circulation models, J. Geophys. Res., 92, 1009-1015.

Hegg, D. A., and P. V. Hobbs (1982), Measurements of sulfate production in natural clouds, Atmos. Environ., 16, 2663-2668.

Hodur, R. M. (1997), The Naval Research Laboratory's Coupled Ocean/ Atmosphere Mesoscale Prediction System (COAMPS), Mon. Weather Rev., 125, 1414-1430.

Hoell, C., C. O'Dowd, S. Osborne, and D. Johnson (2000), Time-scale analysis of marine boundary layer aerosol evolution: Lagrangian case studies under clean and polluted cloudy conditions, Tellus, Ser. B, 52, $423-438$.

Hudson, J. G. (1993), Cloud condensation nuclei near marine cumulus, J. Geophys. Res., 98, 2693-2702.

Jiang, H. G. Feingold, and W. R. Cotton (2002), Simulations of aerosolcloud-dynamical feedbacks resulting from entrainment of aerosol into the marine boundary layer during the Atlantic Stratocumulus Transition Experiment, J. Geophys. Res., 107(D24), 4813, doi:10.1029/ 2001JD001502.

Johnson, D. W., et al. (2000), Observations of the evolution of the aerosol, cloud and boundary-layer characteristics during the 1st ACE-2 Lagrangian experiment, Tellus Ser. B, 52, 348-374.

Jones, A., D. L. Roberts, and A. Slingo (1994), A climate model study of indirect radiative forcing by anthropogenic sulphate aerosols, Nature, $370,450-453$.

Khairoutdinov, M. P., and Y. L. Kogan (1999), A large eddy simulation model with explicit microphysics: Validation against aircraft observations of a stratocumulus-topped boundary layer, J. Atmos. Sci., 56, $2115-$ 2131

Khairoutdinov, M., and Y. Kogan (2000), A new cloud physics parameterization in a Large-Eddy Simulation model of marine stratocumulus, Mon. Weather Rev, 128, 229-243.

Kogan, Y. L. (1991), The simulation of a convective cloud in a 3-D model with explicit microphysics. Part I: Model description and sensitivity experiments, J. Atmos. Sci., 48, 1160-1189.

Kogan, Y. L., M. P. Khairoutdinov, D. K. Lilly, Z. N. Kogan, and Q. Liu (1995), Modeling of stratocumulus cloud layers in a large eddy simulation model with explicit microphysics, J. Atmos. Sci., 52, 2923-2940.

Lieput, B. G., and U. Lohmann (2001), A comparison of sulfate observations and ECHAM4-GCM experiments and its relevance to the indirect aerosol effect, J. Clim., 14, 1078-1091.

Liu, Q., Y. L. Kogan, D. K. Lilly, D. W. Johnson, G. E. Innis, P. A. Durkee, and K. Nielson (2000), LES modeling of ship track formation and its sensitivity to boundary layer structure, J. Atmos. Sci., 57, 2779-2791.

Martin, G. M., D. W. Johnson, and A. Spice (1994), The measurement and parameterization of effective radius of droplets in warm stratocumulus clouds, J. Atmos. Sci., 51, 1823-1842.

Mechem, D. B., and Y. L. Kogan (2003), Simulating the transition from drizzling marine stratocumulus to boundary layer cumulus with a mesoscale model, Mon. Weather Rev., 131, 2342-2360.

Mellor, G. L., and T. Yamada (1982), Development of a turbulence closure model for geophysical fluid problems, Rev. Geophys., 20, 851-875.

Mishchenko, M. I., L. D. Travis, W. B. Rossow, B. Cairns, B. E. Carlson, and Q. Han (1997), Retrieving CCN column density from single-channel measurements of reflected sunlight over the ocean: A sensitivity study, Geophys. Res. Lett., 24, 2655-2658.

Moeng, C.-H., et al. (1996), Simulation of a stratocumulus-topped PBL: Intercomparison among different numerical codes, Bull. Am. Meteorol. Soc., $57,3627-3643$.

Müller, G., and B. Brümmer (1999), Roll convection within an arctic coldair outbreak: Interpretation of in situ aircraft measurements and spaceborne SAR imagery by a three-dimensional atmospheric model, Mon Weather Rev, 127, 363-380.

O'Dowd, C. D., M. H. Smith, A. D. Kaye, and J. Lowe (1996), The relative importance of NSS-sulphate and sea-salt aerosol to the marine $\mathrm{CCN}$ population, paper presented at 12th International Conference on Clouds and Precipitation, Int. Comm. on Clouds and Precip., Zurich, Switzerland.

O'Dowd, C. D., M. H. Smith, I. E. Consterdine, and J. A. Lowe (1997), Marine aerosol, sea-salt, and the marine sulphur cycle: A short review, Atmos. Environ., 31(1), 73-80.

Osborne, S. R., et al. (2000), Evolution of the aerosol, cloud and boundarylayer dynamic and thermodynamic characteristics during the 2nd Lagrangian experiment of ACE-2, Tellus, Ser. B, 52, 375-400. 
Pandis, S. N., L. M. Russell, and J. H. Seinfeld (1994), The relationship between DMS flux and $\mathrm{CCN}$ concentration in remote marine regions, J. Geophys. Res., 99, 16,945-16,957.

Pawloska, H., and J.-L. Brenguier (2003), Microphysical properties of stratocumulus clouds during ACE-2, Tellus, Ser. B, 52, 867-886.

Raes, F. (1995), Entrainment of free tropospheric aerosols as a regulating mechanism for cloud condensation nuclei in the remote marine boundary layer, J. Geophys. Res., 100, 2893-2903.

Shao, Q., and D. A. Randall (1996), Closed mesoscale cellular convection driven by cloud-top radiative cooling, J. Atmos. Sci., 53, 2144-2165.

Stevens, B., W. R. Cotton, G. Feingold, and C. Moeng (1998), Large-eddy simulations of strongly precipitating, shallow, stratocumulus-topped boundary layers, J. Atmos. Sci., 55, 3616-3638.

Stevens, B., et al. (2005), Evaluation of large-eddy simulations via observations of nocturnal marine stratocumulus, Mon. Weather Rev., 133, $1443-1462$.

Twomey, S. (1977), The influence of pollution on the short wave albedo of clouds, J. Atmos. Sci., 34, 1149-1152.
Vali, G., R. D. Kelly, J. French, S. Haimov, D. Leon, R. E. McIntosh, and A. Pazmany (1998), Finescale structure and microphysics of coastal stratus, J. Atmos. Sci., 55, 3540-3564.

Van Dingenen, R., F. Raes, J.-P. Putaud, A. Virkkula, and M. Mangoni (1999), Processes determining the relationship between aerosol number and non-sea-salt sulfate mass concentrations in the clean and perturbed marine boundary layer, J. Geophys. Res., 104, 8027-8038.

VanZanten, M. C., B. Stevens, G. Vali, and D. H. Lenschow (2005), Observations of drizzle in nocturnal marine stratocumulus, J. Atmos. Sci., 62, 88-106.

Wood, R. (2005a), Drizzle in stratiform boundary layer clouds. Part I: Vertical and horizontal structure, J. Atmos. Sci., 62, 3011-3033.

Wood, R. (2005b), Drizzle in stratiform boundary layer clouds. Part II: Microphysical aspects, J. Atmos. Sci., 62, 3034-3050.

Wood, R. (2006), Rate of loss of cloud droplets by coalescence in warm clouds, J. Geophys. Res., doi:10.1029/2006JD007553, in press.

Y. L. Kogan, D. B. Mechem, and P. C. Robinson, Cooperative Institute for Mesoscale Meteorological Studies, University of Oklahoma, 100 Eas Boyd, Room 1110, Norman, OK 73019-1011, USA. (dmechem@ou.edu) 